
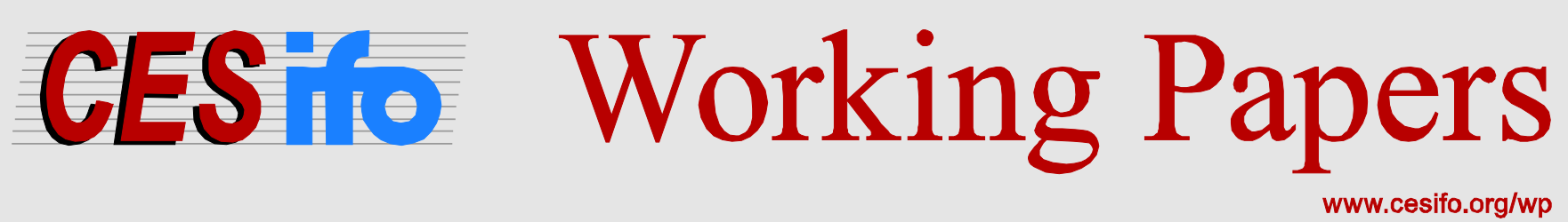

\title{
Panel Data Gravity Models of International Trade
}

\author{
Badi H. Baltagi \\ Peter Egger \\ Michael Pfaffermayr
}

\author{
CESIFO WORKING PAPER NO. 4616 \\ CATEGORY 8: TRADE POLICY \\ JANUARY 2014
}
An electronic version of the paper may be downloaded
- from the SSRN website: Www.SSRN.com
- from the RePEc website: Www.RePEc.org
- from the CESifo website: www.CESifo-group.org/wp

\section{CESifo}




\title{
Panel Data Gravity Models of International Trade
}

\begin{abstract}
One of the oldest and largest literatures in empirical economics is concerned with the estimation of demand and supply of goods, services, and factors across national or subnational borders (see Leamer and Levinsohn, 1995). The respective empirical models specified and estimated are often referred to as gravity models, accruing to their functionalform similarity to Newton's law of gravity in physics. As Newton's model, gravity models of international trade or factor flows are (at least) double-indexed, involving a region or country of origin and a region or country of destination. Pooling such demand equations across pairs or regional units or even across cross-sectional units and time inevitably leads to a panel data structure of the data. This chapter is concerned with a host of issues that arise with the estimation of such models, respecting their panel econometric generic structure. The issues covered range from the estimation of double-indexed versus higher-indexed models, the estimation of fixed effects versus random effects models, issues of endogeneity, of approximation, estimation with missing or zero trade flow data, structural versus reducedform estimation, the role of dynamics or cross-sectional dependence, and issues with specific applications.
\end{abstract}

JEL-Code: C230, C120, F140.

Keywords: panel data, gravity models, international trade.

Badi H. Baltagi

Department of Economics \& Center for

Policy Research / The Maxwell School

Syracuse University

USA - Syracuse, NY 13244-1020

bbaltagi@maxwell.syr.edu
Peter Egger

ETH Zurich

Weinbergstr. 35

Switzerland - 8092 Zurich

egger@kof.ethz.ch

\author{
Michael Pfaffermayr \\ Department of Economics \\ University of Innsbruck \\ Universitätsstr. 15 \\ Austria - 6020 Innsbruck \\ Michael.Pfaffermayr@uibk.ac.at
}




\section{Introduction}

This chapter focuses on the estimation of gravity models of bilateral trade of goods (or services) and other bilateral international outcomes such as foreign direct investment or migration stocks or flows. Gravity models assume that these bilateral relationships can be modelled as a multiplicative function of the economic masses of two economies (incomes, expenditures, or endowments), the inverse of economic distance (trade costs, investment costs, or migration costs), and some constant, akin to Isaac Newton's law of gravity. Stochastic versions of this model have become the empirical workhorse to study gravity models since the 19th century. The estimates obtained (especially for bilateral geographical distance) reflect some of the most robust relationships not only in international economics but in economics at large (see Leamer and Levinsohn, 1995).

This chapter discusses the application of panel econometric methods to gravity modeling. It also discusses single cross section as well as repeated cross sections of country pairs over time. The nature of the data calls for panel econometric methods due to their inherent double and even triple indexation.

\section{Theoretical background}

\section{$2.1 \quad$ Fundamentals}

A large class of new trade models generate aggregate bilateral demand equations of consumers in country $j=1, \ldots, F$ from producers in country $i=1, \ldots, E$ at time $s=1, \ldots, S$ of the following isomorphic form:

$$
X_{i j s}=l_{i s} m_{j s} t_{i j s}^{b}
$$


where $X_{i j s}$ are aggregate, nominal bilateral exports, $l_{i s}$ are exporter-timespecific factors, $m_{j s}$ are importer-time-specific factors, $t_{i j s}$ is a compact measure of all bilateral (and potentially time-specific) ad-valorem trade costs, and $b$ is referred to as the partial elasticity of trade (flows) with respect to variable trade costs.

The interpretation of $l_{i s}$ and $m_{j s}$ depend upon the underlying guiding theoretical model. Leading examples in the literature are the following. Krugman (1980) presents a model which has been outlined for multiple countries in Bergstrand, Egger, and Larch (2013), where $l_{i s}$ is the product of country-specific numbers of identical (single-product) monopolistically competitive firms and producer (mill) prices of identical prices per product, where the latter is exponentiated by $b$. Krugman's (1980) model is one of a love of variety, and $b$ in that context reflects both (one minus) the elasticity of substitution among varieties (i.e., firms' products) and (one minus) the elasticity of demand. Eaton and Kortum (2002) formulate a Ricardian model of heterogeneous firms in each country which differ in terms of their productivity. $l_{i s}$ represents the product of the average level of productivity in a country and marginal production costs. This product is exponentiated by $b$, which captures the dispersion of productivity across firms. Anderson and van Wincoop (2003) formulate an endowment-economy model along the lines of Anderson (1979), where $l_{i s}$ represents the product of a preference mass parameter and the unique producer price relevant to country-time $i s$, both exponentiated by $b$. In their context, $b$ measures (one minus) the elasticity of substitution between products from different countries of origin. In any one of those models, $Y_{i s}=\sum_{j=1}^{F} X_{i j s}$ measures total sales of country $i$ of $X_{i s}$ in period $s$. This corresponds to gross domestic product, if there is a single sector or activity. Moreover, in any one of the aforementioned 
models in case of $E=F$ it holds that $Y_{j s}=\sum_{i=1}^{E} X_{i j s}, m_{j s} \equiv \frac{Y_{j s}}{\sum_{i=1}^{E} l_{i s} t_{i j s}^{b}}$ and $Y_{i s}=\sum_{j=1}^{F} X_{i j s}=l_{i s} \sum_{j=1}^{F} m_{j s} t_{i j s}^{b}$.

While the frameworks of Eaton and Kortum (2002), Anderson and van Wincoop (2003), or Bergstrand, Egger, and Larch (2013) are based on consumer preferences and firms' supply behavior which ensures that all countrypairs trade with each other, zero bilateral trade can be generated by other frameworks. For instance, in the probabilistic model of Eaton and Kortum (2002), zero trade can not occur in expectation but very well in realization. The models of Anderson (1979) and Krugman (1980) can generate zero trade flows if fixed trade costs are considered beyond variable trade costs, no matter whether firms are heterogeneous in terms of productivity (see Helpman, Melitz, and Rubinstein, 2008) or not (see Egger and Larch, 2011, and Egger, Larch, Staub, and Winkelmann, 2011). The latter study considers endowment-economy versions with zero trade flows.

\subsection{Multiple sectors}

An extension of the model in Section 2.1 to the case of multiple sectors is straightforward. For instance, if consumers spend a fixed share of their income per product, the model extension is particularly easy. Bilateral demand per product or sector can be represented by an equation such as (1) and all subscripts have to be augmented by a sector index, say, $h=1, \ldots, H$. Moreover, $Y_{i h s}$ would be sales per sector $h$ of country $i$ in year $s$, and GDP would be $Y_{i s}=\sum_{h=1}^{H} Y_{i h s}=\sum_{h=1}^{H} \sum_{j=1}^{F} X_{i j h s}$. Sector-level model versions have been formulated by Anderson (1979) as well as Anderson and van Wincoop (2003) for endowment-economy models, by Levchenko and Zhang (2012) for a Ricardian model, and by Egger, Larch, and Staub (2012) for a 
Krugman-type model.

\subsection{Outcomes beyond goods trade}

While the aforementioned models have been introduced originally to specify bilateral demand for goods, models as in Section 2.1 have recently been derived for services trade (see Egger, Larch, and Staub, 2012), for portfolio capital flows (see Okawa and van Wincoop, 2013), for foreign direct investment (see Baier, Bergstrand, and Gainer, 2012), ${ }^{1}$ and for migration (see Anderson, 2011). ${ }^{2}$

\section{Cross section of country pairs}

Notice that the model in (1) is triple-indexed. Hence, even an analysis of a cross section of country pairs (based on a single year $s$ or an average across several years) in essence involves panel data, although the format tends to be quadratic (with about as many exporting countries as there are importing ones) resulting in a two-way panel. Let us specify the deterministic part of bilateral exports (or imports) $\ln \left(l_{i} m_{j} t_{i j}^{b}\right)$ in (1) as $h_{i j} \gamma+\alpha$, where $h_{i j}$ is a $1 \times k$ vector of observable determinants, $\gamma$ is a conformable (unknown) parameter vector, and $\alpha$ is a constant. Moreover, let us introduce a logadditive stochastic term $e_{i j}$ and write the stochastic counterpart to equation (1) in a cross section as

$$
X_{i j}=\exp \left(h_{i j} \gamma+\alpha+e_{i j}\right), i=1, \ldots, E, j=1, \ldots, F .
$$

\footnotetext{
${ }^{1}$ Earlier studies integrating goods trade and foreign direct investment were conducted by Eaton and Tamura (1994) and Egger and Pfaffermayr (2004b).

${ }^{2}$ Gravity equations have also been estimated for remittances of migrants (see Docquier, Rapoport, and Salomone, 2010).
} 
Using $x_{i j} \equiv \ln X_{i j}$, the log-linear form of the model is thus given as

$$
x_{i j}=h_{i j} \gamma+\alpha+e_{i j}
$$

Since the model is double-indexed, it is reasonable to assume that $e_{i j}$ exhibits a two-way error component structure of the form

$$
e_{i j}=u_{i}+v_{j}+\varepsilon_{i j}
$$

where $\varepsilon_{i j}$ are iid random disturbances and $u_{i}$ and $v_{j}$ capture exporter and importer specific effects. In matrix form, the model can be written as

$$
\begin{aligned}
& x=h \gamma+\alpha \iota_{E F}+e \\
& e=\Delta_{u} u+\Delta_{v} v+\varepsilon
\end{aligned}
$$

where $x$ is an $E F \times 1$ vector and the dimensions of $h, u$, and $v$ are, respectively, $E F \times k, E \times 1$, and $F \times 1$. In general, we denote by $\iota_{E F}$ a column vector of ones whose dimension is $E F$. Assume that the data are sorted first by exporter and then by importer country ( $i$ is the slow index and $j$ the fast one). Then, the (indicator variables) design matrices $\Delta_{u} \equiv\left(I_{E} \otimes \iota_{F}\right)$ and $\Delta_{v} \equiv\left(\iota_{E} \otimes I_{F}\right)$, where $I_{E}$ and $I_{F}$ are identity matrices of dimensions $E$ and $F$, respectively. In case of an unbalanced panel one obtains the design matrices $\Delta_{u}$ and $\Delta_{v}$ by skipping the rows of $\left(I_{E} \otimes \iota_{F}\right)$ and $\left(\iota_{E} \otimes I_{F}\right)$ that correspond to missing values. Depending on the assumptions on the importer and importer specific terms $(u$ and $v)$ several econometric models can be specified. ${ }^{3}$

\footnotetext{
${ }^{3}$ In general, one may use $\ln \frac{X_{i j}}{l_{i} m_{j}}$ as a dependent variable instead of $x_{i j}$. Then, $h_{i j} \gamma$ would measure $b \ln t_{i j}$. In particular, this may be desirable with structural (iterative) model estimation. Of course, this is only relevant with random effects estimates, since in a fixed effects $\ln l_{i} m_{j}$ are fully captured by the exporter and importer fixed effects.
} 


\subsection{The two-way fixed effects model}

Treating $u_{i}$ and $v_{j}$ as fixed parameters, i.e., subsuming observed and unobserved exporter specific factors ( $\operatorname{such}$ as $\ln l_{i}$ ) and importer factors (such as $\ln m_{j}$ ) of the generic gravity model into the effects, estimation of the parameters $\gamma$ is straight forward, even if the panel is unbalanced.

Following Davis (2002), define the projection matrices $P_{[A]}=A\left(A^{\prime} A\right)^{-} A^{\prime}$, where ${ }^{-}$denotes the pseudo inverse, and $Q_{[A]}=I-P_{[A]}$. His Lemma 1 states that for conformable matrices $\Delta=\left(\Delta_{u}, \Delta_{v}\right)$, it follows that $P_{[\Delta]}=$ $P_{\left[\Delta_{u}\right]}+P_{\left[Q_{\left[\Delta_{u}\right]} \Delta_{u}\right]}$. The within transformation that eliminates fixed exporter and importer effects is therefore defined as

$$
\begin{aligned}
Q_{[\Delta]} & =I-P_{[\Delta]}=Q_{\left[\Delta_{u}\right]}-P_{\left[Q_{\left[\Delta_{u}\right]} \Delta_{v}\right]} \\
& =Q_{\left[\Delta_{u}\right]}-Q_{\left[\Delta_{u}\right]} \Delta_{v}\left(\Delta_{v} Q_{\left[\Delta_{u}\right]} \Delta_{v}\right)^{-} Q_{\left[\Delta_{u}\right]} \Delta_{v}
\end{aligned}
$$

Estimation is thus straight forward as one can apply OLS to the within transformed model of the form

$$
Q_{[\Delta]} x=Q_{[\Delta]} h \gamma+Q_{[\Delta]} \varepsilon
$$

to obtain consistent estimates of $\gamma$. To guard against equicorrelation in the data due to the presence of common shocks to exporters and importers it may be advisable to use two-way clustering when estimating the variance of the estimated parameters (see Wooldridge, 2003).

\subsection{The two-way random effects model}

Under the random effects assumption exporter and importer effects are as-

sumed to be random with $u_{i}\left|h \sim i i d\left(0, \sigma_{u}^{2}\right), v_{j}\right| h \sim i i d\left(0, \sigma_{v}^{2}\right), E\left[u_{i} v_{j} \mid h\right]=0$ as well as $E[u \mid h]=0$ and $E[v \mid h]=0$. The variance-covariance of the disturbances in the two-way gravity model with random effects is then given by 
(see Baltagi, 2008, p. 37)

$$
\Omega_{e}:=E\left[e e^{\prime}\right]=\sigma_{u}^{2} \Delta_{u} \Delta_{u}^{\prime}+\sigma_{v}^{2} \Delta_{v} \Delta_{v}^{\prime}+\sigma_{\varepsilon}^{2} I_{E F}
$$

For the unbalanced panel case we define

$$
\begin{aligned}
\widetilde{\Delta}_{E} & =\Delta_{u}^{\prime} \Delta_{u}+\frac{\sigma_{\varepsilon}^{2}}{\sigma_{u}^{2}} I_{E} \\
\widetilde{\Delta}_{F} & =\Delta_{v}^{\prime} \Delta_{v}+\frac{\sigma_{\varepsilon}^{2}}{\sigma_{u}^{2}} I_{F} \\
\widetilde{P} & =\widetilde{\Delta}_{F}-J_{F E} \widetilde{\Delta}_{E}^{-1} J_{E F}^{\prime} \\
V & =I_{n}-\Delta_{u} \widetilde{\Delta}_{E}^{-1} \Delta_{u}^{\prime}
\end{aligned}
$$

where $n$ is the overall number of observations. Wansbeek and Kapteyn (1989) obtain the inverse variance-covariance matrix as

$$
\Omega_{e}^{-1}=V-V \Delta_{v} \widetilde{P}^{-1} \Delta_{v}^{\prime} V
$$

One can use GLS-estimation, i.e. applying OLS to the GLS-trasnformed

data using $\sigma_{\varepsilon} \Omega_{e}^{-1 / 2} x$ and $\sigma_{\varepsilon} \Omega_{e}^{-1 / 2} h$. An important advantage of the random effects specification is that the explanatory variables, $h$, may include variables that vary only in the exporter or importer dimension, but not in both. However, the main drawback of the random effects specification lies in its restrictive exogeneity assumptions that require zero correlation of the explanatory variables with both the random exporter and importer effects.

\section{Three-way panels of country pairs - repeated observation of cross section data over time}

Gravity models with time variation typically involve a large number of country-pairs but a short time $\operatorname{span}(E F \gg S)$. In this context, the 
workhorse model is usually a two-way model with country-pair and time effects of the form

$$
x_{i j s}=h_{i j s} \gamma+\alpha+u_{i j}+v_{s}+\varepsilon_{i j s}
$$

(see Egger and Pfaffermayr, 2003), using an obvious amendment of the notation for cross-section data in equation (2).

However, unless $h_{i j s}$ includes structural or approximated measures of $l_{i s}$ and $m_{j s}$, this specification is not able to account for time varying countrytime specific factors such as producer and consumer goods price indices, etc. In the absence of such terms, $h_{i j s}$ would be endogenous and the standard estimates of $\gamma$ ignoring this endogeneity will be inconsistent. The latter could be avoided by including fixed exporter-time and importer-time effects in addition to (fixed or random) country-pair effects. Baltagi, Egger, and Pfaffermayr (2003) proposed and analyzed such a specification with fixed exporter-time, importer-time, and exporter-importer effects of the form:

$$
\begin{aligned}
x_{i j s}= & h_{i j s} \gamma+\alpha+u_{i j}+v_{i s}++w_{j s}+\varepsilon_{i j s} \\
& \text { or in vector form } \\
x= & h \gamma+\Delta_{u} u+\Delta_{v} v+\Delta_{w} w+\tau \beta+\varepsilon,
\end{aligned}
$$

where again $\Delta_{u}, \Delta_{v}$ and $\Delta_{w}$ denote the corresponding dummy design matrices. Clearly, only the coefficients $\gamma$ of the $i j s$-indexed explanatory variables may be identified with such an approach.

Applying Davis' (2002) Lemma twice (as in his Corollary 1), yields the projection on $\Delta=\left[\Delta_{u}, \Delta_{v}, \Delta_{w}\right]$

$$
P_{[\Delta]}=P_{\left[\Delta_{u}\right]}+P_{\left[\mathbf{Q}_{\left[\Delta_{u}\right]} \Delta_{v}\right]}+P_{\left[\mathbf{Q}_{\left[Q_{\left[\Delta_{u}\right]} \Delta_{v}\right]} \mathbf{Q}_{\left[\Delta_{v}\right]} \Delta_{w}\right]}
$$


The within transformation is therefore given by

$$
\begin{aligned}
& Q_{[\mathbf{Z}]}=I-P_{[\Delta]}=Q_{\left[\Delta_{u}\right]}-P_{\left[\mathbf{Q}_{\left[\Delta_{u}\right]} \Delta_{v}\right]}-P_{\left[\mathbf{Q}_{\left[Q_{\left[\Delta_{u}\right]} \Delta_{v}\right]} \mathbf{Q}_{\left[\Delta_{v}\right]} \Delta_{w}\right]} \\
& P_{\left[\mathbf{Q}_{\left[\Delta_{u}\right]} \Delta_{v}\right]}=Q_{\left[\Delta_{u}\right]} \Delta_{v}\left(\Delta_{v}^{\prime} Q_{\left[\Delta_{u}\right]} \Delta_{v}\right)^{-} \Delta_{v} Q_{\left[\Delta_{u}\right]} \\
& P_{\left[\mathbf{Q}_{\left[Q_{\left[\Delta_{u}\right]} \Delta_{v}\right]} \mathbf{Q}_{\left[\Delta_{v}\right]} \Delta_{w}\right]}=Q_{\left[\Delta_{u}\right]} Q_{\left[\mathbf{Q}_{\left[\Delta_{u}\right]} \Delta_{v}\right]} \Delta_{w}\left(\Delta_{w}^{\prime} Q_{\left[\Delta_{u}\right]} Q_{\left[\mathbf{Q}_{\left[\Delta_{u}\right]} \Delta_{v}\right]} \Delta_{w}\right)^{-} \Delta_{w}^{\prime} Q_{\left[\Delta_{u}\right]} Q_{\left[\mathbf{Q}_{\left[\Delta_{u}\right]} \Delta_{v}\right]}
\end{aligned}
$$

In the balanced case with $N \equiv E F$ observations, this generates a blockdiagonal structure, if one sorts the data first by exporter, then importer, and lastly by time to obtain

$$
\begin{aligned}
& \text { exporter-importer indicators : } \Delta_{u}=\left(I_{N} \otimes I_{N} \otimes \iota_{S}\right) \\
& \text { exporter year indicators : } \Delta_{v}=\left(\iota_{N} \otimes I_{N} \otimes I_{S}\right) \\
& \text { importer year indicators : } \Delta_{w}=\left(I_{N} \otimes \iota_{N} \otimes I_{S}\right) \text {. }
\end{aligned}
$$

Davis (2002) also discusses the random effects and mixed random and fixed specifications of this model. In practice, many researchers exploit the fact that $E S$ and $F S$ are much smaller than $E F$. They use the $E S$ exportertime, FS importer-time indicator variables, in conjunction with a withintransformation to wipe out the $E F$ country-pair fixed effects. This obtains identical estimates of $\gamma$ as the three-way within transformation following Davis (2002).

\section{A smoargasboard of empirical topics}

\subsection{Econometric issues}

\subsubsection{Heteroskedasticity}

\section{The case of cross-section data:}

If one estimates gravity models in levels rather than in logs heteroskedasticity typically arises due the large variation in country size. To account for 
heteroskedasticity, Santos Silva and Trenreyro (2006) suggest estimating the gravity model in levels rather than in logs. A by-product of this strategy is that information on zero bilateral trade flows may be used when identifying parameters. They propose a non-linear, exponential-family gravity model with an additive error term of the form:

$$
X_{i j}=\exp \left(h_{i j} \gamma+\alpha+u_{i}+v_{j}\right)+\varepsilon_{i j}, i=1, \ldots, E, j=1, \ldots, F .
$$

This model may be easily estimated by either assuming that $u_{i}$ and $v_{j}$ are zero (as Santos Silva and Tenreyro, 2006, did) or by assuming that $u_{i}$ and $v_{j}$ are fixed and part of $h_{i j} \gamma$. If $X_{i j}=0, \varepsilon_{i j}=-\exp \left(h_{i j} \gamma+\alpha+u_{i}+v_{j}\right)$. Following McCullagh and Nelder (1989), Santos Silva and Trenreyro (2006) assume that the conditional variance is proportional to the conditional mean: $V\left[X_{i j} \mid h_{i j}\right] \propto E\left[X_{i j} \mid h_{i j}\right]=\exp \left(h_{i j} \gamma+\alpha+u_{i}+v_{j}\right)$. The first order conditions for weighted nonlinear least squares are given by:

$$
\begin{aligned}
\sum_{i=1}^{E} \sum_{j=1}^{F}\left(X_{i j}-\exp \left(h_{i j} \gamma+\alpha+u_{i}+v_{j}\right)\right) h_{i j} & =0 \\
\sum_{i=1}^{E} \sum_{j=1}^{F}\left(X_{i j}-\exp \left(h_{i j} \gamma+\alpha+u_{i}+v_{j}\right)\right) 1 & =0 \\
\sum_{j=1}^{F}\left(X_{i j}-\exp \left(h_{i j} \gamma+\alpha+u_{i}+v_{j}\right)\right) 1 & =0 \\
\sum_{i=1}^{E}\left(X_{i j}-\exp \left(h_{i j} \gamma+\alpha+u_{i}+v_{j}\right)\right) 1 & =0 .
\end{aligned}
$$

These are numerically identical to the Poisson pseudo-maximum-likelihood (PPML) estimator that is often used for count data. Note that under pseudo-maximum-likelihood estimation, only the conditional mean has to be specified correctly to obtain consistent parameter estimates. Since, both $E$ and $F$ are large but (much) smaller than $E F$, one can add exporter 
and importer dummies to the model to account for unobserved variables that vary either in the exporter or the importer dimension. Let us define $\widehat{\mu}_{i j} \equiv \exp \left(h_{i j} \widehat{\gamma}+\widehat{\alpha}+\widehat{u}_{i}+\widehat{v}_{j}\right)$ and $z_{i j}=\left(h_{i j}, \Delta_{u}, \Delta_{v}\right)$ with $\Delta_{u}$ denoting exporter indicators and $\Delta_{v}$ importer indicators. Following, White (1982), one can show that the PPML estimator is asymptotically normal and the corresponding variance-covariance matrix can be estimated as

$V(\widehat{\gamma}, \widehat{\alpha})=\left(\sum_{i=1}^{E} \sum_{j=1}^{F} \widehat{\mu}_{i j} z_{i j} z_{i j}^{\prime}\right)^{-1}\left(\sum_{i=1}^{E} \sum_{j=1}^{F} V\left(X_{i j} \mid z_{i j}\right) z_{i j} z_{i j}^{\prime}\right)\left(\sum_{i=1}^{E} \sum_{j=1}^{F} \widehat{\mu}_{i j} z_{i j} z_{i j}^{\prime}\right)^{-1}$.

Clearly, if the data are generated in full (!) compliance with the model in Section 2.1 (invoking multilateral trade balance), $\exp \left(\widehat{u}_{i}\right)$ and $\exp \left(\widehat{v}_{j}\right)$ are consistent estimates of the cross-section counterpart $l_{i}$ and $m_{j}$ in equation (1) (see Fally, 2012). To see this, use $\lambda_{i j}=\exp \left(h_{i j} \gamma+\alpha\right), l_{i}=\exp \left(u_{i}\right)$, and $m_{j}=\exp \left(v_{j}\right)$ to write the first-order conditions of the Poisson likelihood (15) with respect to the $k$ th variable in $h_{i j}$ and to $u_{i}$ and $v_{j}$ as

$$
\begin{aligned}
\frac{\partial \ln L}{\partial \lambda_{i j}} \frac{\partial \lambda_{i j}}{\partial \gamma_{k}} & =\sum_{i=1}^{E} \sum_{j=1}^{F}\left(-l_{i} m_{j}+\frac{X_{i j}}{\lambda_{i j}}\right) h_{i j, k}=0 \\
\frac{\partial \ln L}{\partial l_{i}} & =\sum_{j=1}^{F}\left(-\lambda_{i j} m_{j}+\frac{X_{i j}}{l_{i}}\right)=0 \rightarrow \widehat{l}_{i} \sum_{j=1}^{F} \lambda_{i j} m_{j}=\sum_{j=1}^{F} X_{i j} \\
\frac{\partial \ln L}{\partial m_{j}} & =\sum_{i=1}^{E}\left(-\lambda_{i j} l_{i}+\frac{x_{i j}}{m_{j}}\right)=0 \rightarrow \widehat{m}_{j} \sum_{i=1}^{E} \lambda_{i j} l_{i}=\sum_{i=1}^{E} X_{i j} .
\end{aligned}
$$


The latter two conditions imply

$$
\begin{aligned}
\sum_{i=1}^{E} X_{i j} & =\sum_{i=1}^{E} \lambda_{i j} \widehat{l}_{i} \widehat{m}_{j} \\
\sum_{j=1}^{F} X_{i j} & =\sum_{j=1}^{F} \lambda_{i j} \widehat{l}_{i} \widehat{m}_{j} \\
\sum_{i=1}^{E} \sum_{j=1}^{F} X_{i j} & =\sum_{i=1}^{E} \sum_{j=1}^{F} \lambda_{i j} \widehat{l}_{i} \widehat{m}_{j}
\end{aligned}
$$

In a structural gravity model, as in Section 2.1, setting $Y \lambda_{i j} l_{i} m_{j}=$ $t_{i j}^{b} l_{i} m_{j}$ with $Y=\sum_{j=1}^{F} Y_{j}$ denoting world expenditures on goods, bilateral goods exports (or imports) are defined as

$$
X_{i j}=Y \lambda_{i j} l_{i} m_{j}
$$

Denoting income and expenditure shares as $\theta_{i}=Y_{i} / Y$ and $\theta_{j}=Y_{j} / Y$,

$$
\theta_{i}=l_{i} \sum_{h=1}^{F} \lambda_{i h} m_{h}, \quad \theta_{j}=m_{j} \sum_{h=1}^{F} \lambda_{h j} l_{h} .
$$

It is now readily seen that the fixed effects estimates $\exp \left(\widehat{v}_{i}\right)$ and $\exp \left(\widehat{w}_{j}\right)$ are consistent estimates of $l_{i}$ and $m_{j}$ in (1) as they solve

$$
\begin{aligned}
\theta_{i} & =\frac{1}{Y} \sum_{j=1}^{F} X_{i j}=\frac{1}{Y} \sum_{j=1}^{F} \lambda_{i j} \widehat{l}_{i} \widehat{m}_{j} \\
\theta_{j} & =\frac{1}{Y} \sum_{i=1}^{E} X_{i j}=\frac{1}{Y} \sum_{i=1}^{E} \lambda_{i j} \widehat{l}_{i} \widehat{v}_{j} \\
1 & =\frac{1}{Y} \sum_{i=1}^{E} \sum_{j=1}^{F} X_{i j}=\frac{1}{Y} \sum_{i=1}^{E} \sum_{j=1}^{F} \lambda_{i j} \widehat{l}_{i} \widehat{m}_{j} .
\end{aligned}
$$

With this data generating process, the exporter and importer fixed effects in the PPML-model would be structural estimates of the terms $l_{i}$ and $m_{j}$. Yet, evidence suggests that this is not the case, and the data generating 
process of bilateral export and import flows appears to violate some of the fundamental assumptions (see Egger, Larch, and Staub, 2012). Among others, the PPML estimator has been applied to cross-sectional gravity models by Santos Silva and Silvana Tenreyro (2009) and Egger, Staub, Larch, and Winkelmann (2011).

\section{The case of data with repeated cross sections (three-way panels):}

The PPML-estimator discussed for the (two-way) cross-sectional model can also be applied to the two-way (or even three-way) panel models with a large number of country pairs and a small number of time periods $(N=E F \gg S)$. Subsuming $h_{i j s}$, time indicators, and the constant into $z_{i j s}$ with conformable parameter $\phi$, the model becomes

$$
X_{i j s}=\exp \left(z_{i j s} \phi+u_{i j}\right)+\varepsilon_{i j s}, i=1, \ldots, E, j=1, \ldots, F, s=1, \ldots, S
$$

The underlying likelihood may be based on $X_{i j s} \sim$ iid $\mathcal{P}\left(u_{i j} e^{z_{i j s} \phi}\right)$. Defining $\lambda_{i j s}=\exp \left(z_{i j s} \phi\right)$, Cameron and Trivedi (2005) demonstrate that the first order condition for $u_{i j}$ yields $\widehat{u}_{i j}=\sum_{s=1}^{S} x_{i j s} / \sum_{s=1}^{S} \ln \lambda_{i j s}$ so that one can eliminate (concentrate out) $u_{i j}$ and there is no incidental parameters problem (akin to the one-way within-transformation with a large number of cross sections and a short time period in a linear panel model).

For any generic variable $z_{k, i j s}$, the score function of the concentrated

likelihood uses the transformed values $z_{k, i j s}-\frac{\lambda_{i j s}}{\lambda_{i j}} \bar{z}_{k, i j}$, where a bar indicates averages of a variable across all years in the data, to obtain:

$$
\frac{\left.\partial \ln L\left(\phi, u_{i j}\right)\right)}{\partial \phi}=\sum_{i=1}^{E} \sum_{j=1}^{F} \sum_{s=1}^{S}\left[\lambda_{i j s}\left(z_{i j s}-\frac{\lambda_{i j s}}{\bar{\lambda}_{i j}} \bar{z}_{i j}\right)\right] .
$$

The fixed effects Poisson estimator has strong robustness properties as it is consistent under the conditional mean assumption, whereby $E\left[X_{i j s} \mid z_{i j s}, u_{i j}\right]=$ 
$\exp \left(u_{i j}\right) e^{\lambda_{i j s} \phi}$. Also the distribution of $z_{i j s}$ does not need to be discrete, and there is no restriction on the dependence of $z_{i j s}$ and $z_{i j s^{\prime}}, s \neq s^{\prime}$, and one can apply PPML (see Wooldridge, 2010). Uniqueness holds under general identification assumptions. However, a similar transformation is not available for the two-way or three-way fixed effects problems. The fixed country-pair effects PPML estimator has been applied with panel data, among others, by Egger and Nelson (2011).

\subsubsection{Zeros and missing data}

\section{The case of cross-section (two-way) data:}

In general, trade data often include a large number of reported zeros or missing trade flows as, e.g., small countries may not have trade relations with all possible trading partners or because statistical offices do not report trade flows below certain thresholds. Non-randomly missing zero trade flows require the estimation of sample selection models or two-part models. For example, the model discussed in Helpman, Melitz, and Rubinstein (2008) naturally leads to a sample selection approach if the disturbances in the outcome equation (log bilateral exports or imports, $x_{i j}$ ) are correlated with those of the selection equation. A latent variable for the propensity of exports from $i$ to $j$ may be defined as

$$
V_{i j}^{*}=f_{i j} \delta+k_{i}+r_{j}+\eta_{i j}
$$

where $f_{i j}$ includes, among other variables, measures of log bilateral trade barriers and log bilateral fixed costs of exporting (or importing). Since variable and fixed costs to trade depend, at least partly, on the same deter- 
minants (such as log bilateral distance), $\delta$ only identifies their joint impact.

$$
\begin{aligned}
& \ln X_{i j}=\left\{\begin{array}{c}
h_{i j} \gamma+u_{i}+v_{j}+\varepsilon_{i j} \text { if } V_{i j}=1 \\
\text { unobserved if } V_{i j}=0
\end{array}\right. \\
& V_{i j}=1\left[\ln V_{i j}^{*}>0\right] \\
& \left(\eta_{i j}, \varepsilon_{i j}\right) \sim N\left[0,\left(\begin{array}{cc}
1 & \rho \sigma_{\varepsilon} \\
\rho \sigma_{\varepsilon} & \sigma_{\varepsilon}^{2}
\end{array}\right)\right] \text {. }
\end{aligned}
$$

The standard sample selection model assumes normality and homoskedasticity. The latter means that $k_{i}$ and $r_{j}$ as well as $u_{i}$ and $v_{j}$ must be assumed as fixed, and they can be identified, since $E F \gg E+F$. The parameters can then be estimated by maximizing the likelihood

$$
\begin{aligned}
\ln L= & \sum_{i=1}^{E} \sum_{j=1}^{F} V_{i j}\left(\ln \Phi\left(\frac{f_{i j} \delta+k_{i}+r_{j}+\frac{\rho}{\sigma_{e}}\left(\ln X_{i j}-h_{i j} \gamma-u_{i}-v_{j}\right)}{\left(1-\rho^{2}\right)^{1 / 2}}\right)\right. \\
& \left.-\sigma_{e} \ln \phi\left(\frac{\ln X_{i j}-h_{i j} \gamma-u_{i}-v_{j}}{\sigma_{e}^{2}}\right)\right) \\
& +\left(1-V_{i j}\right) \ln \Phi\left(f_{i j} \delta+k_{i}+r_{j}\right)
\end{aligned}
$$

Formally, the first order conditions for the score of the likelihood can be solved without exclusion restrictions, although it may be poorly identified if large values of $V_{i j}^{*}$ are not in the data (see Cameron and Trivedi, 2005). Also, two-step estimators that include the estimated mills ratio from a first step may be used. $^{4}$ The main advantage of the sample-selection approach lies in its ability to predict potential unobserved outcomes. This allows intuitive comparative static analysis consistent in broad terms with the model

\footnotetext{
${ }^{4}$ Alternatively, one may use a nonparametric control function approach to correct the estimated model for the conditional mean of the selection model given positive trade flows (see Cameron and Trivedi, 2005).
} 
structures in Section 2.1. Using $x_{i j}=\ln X_{i j}$, this model can be written as

$$
E\left[x_{i j} \mid V_{i j}^{*}>0\right]=h_{i j} \gamma+u_{i}+v_{j}+\rho \sigma_{e} \frac{\phi\left(f_{i j} \delta+k_{i}+r_{j}+\eta_{i j}\right)}{\Phi\left(f_{i j} \delta+k_{i}+r_{j}+\eta_{i j}\right)} .
$$

Sample selection gravity models of this kind have been estimated, among others, by Helpman, Melitz, and Rubinstein (2008), Egger, Larch, Staub, and Winkelmann (2011), and Head and Mayer (2011).

Alternatively, one can rely on a two-part model (see, e.g., Egger, Larch, Staub and Winkelmann, 2011). This model specifies the conditional mean for positive models separately as

$$
E\left[x_{i j} \mid X_{i j}>0\right]=h_{i j} \gamma+u_{i}+v_{j}+\varepsilon_{i j}
$$

and estimates a probit or logit model for the probability to export (or import) as

$$
P\left(V_{i j}^{*}>0\right)=P\left(f_{i j} \delta+k_{i}+r_{j}+\eta_{i j}>0\right)
$$

In both cases the unconditional expectation is then given as

$$
P\left(V_{i j}^{*}>0\right) E\left[x_{i j} \mid X_{i j}>0\right] .
$$

\section{The case of repeated cross-section (three-way) data:}

In case of non-randomly missing bilateral trade flows with time-series-crosssection data, one has to rely on panel data sample selection models as discussed in Wooldridge (1995), Dustmann and Rochina-Barrachina (2007), Semykina and Wooldridge (2010). For ease of notation, and without loss of generality, let us subsume the constant and fixed time effects into $h_{i j s} \gamma$. Furthermore, in line with typical data, let us assume that $E F \gg S$. The sample selection model with (fixed or random) country-pair effects $\left(u_{i j}\right)$ can 
be written as:

$$
\begin{aligned}
x_{i j s} & =\left\{\begin{array}{r}
h_{i j s} \gamma+u_{i j}+\varepsilon_{i j s} \text { if } V_{i j s}=1 \\
\text { unobserved if } V_{i j s}=0
\end{array}\right. \\
V_{i j s} & =1\left[\ln V_{i j s}^{*}>0\right] \\
V_{i j s}^{*} & =f_{i j s} \delta_{s}+k_{i j}+\eta_{i j s}
\end{aligned}
$$

Wooldridge (1995) shows that one can correct for selection bias arising from the correlation of the disturbances $\varepsilon_{i j s}$ and $\eta_{i j s}$ using Mundlak's (1978) and Chamberlain's (1982) ideas. Note the coefficient of $f_{i j s}$ in the selection equation may vary over time.

The conditional expectation $E\left[\varepsilon_{i j s} \mid f_{i j s}, V_{i j s}\right]$ has a complicated nonlinear form. But if $E\left[u_{i j}+\varepsilon_{i j s} \mid f_{i j s}, V_{i j s}\right]=0$, a pooled OLS control function approach on a Mundlak-type model will be consistent, which leads to the specification

$$
\begin{aligned}
x_{i j s} & =h_{i j s} \gamma+\underbrace{\bar{h}_{i j .} \pi_{x, s}+\varsigma_{i j}}_{u_{i j}}+\underbrace{E\left[\varepsilon_{i j s} \mid f_{i j s}, V_{i j s}=1\right]}_{=\gamma E\left[\eta_{i j s} \mid f_{i j s}, V_{i j s}=1\right]}+\nu_{i j s} \\
& =h_{i j s} \gamma+\bar{h}_{i j .} \pi_{x, s}+\varsigma_{i j}+\gamma \lambda_{i j s}+\nu_{i j s} \text { for } V_{i j s}=1
\end{aligned}
$$

where $\nu_{i j s}$ denote the remainder random disturbances and $\varsigma_{i j}$ is a random country-pair effect that comes from parameterizing $u_{i j}$ by a systematic term $\bar{h}_{i j .} \pi_{x, s}$ and a random country pair effect $\varsigma_{i j}$. In addition, $E\left[\nu_{i j s} \mid f_{i j s}, V_{i j s}=\right.$ 1] $=0$ is assumed (see Semykina and Wooldridge, 2010, Assumption 4.1.1, p. 387). For implementation, one estimates for each year $s=1, \ldots, S$ a probit model $P\left(V_{i j s}=1 \mid f_{i j s}\right)=\Phi\left(f_{i j s} \delta_{s}\right)$ to obtain an estimator of the inverse Mills' ratio $\widehat{\lambda}_{i j s}=\lambda\left(f_{i j s} \delta_{s}\right)$. Then one can use pooled OLS to estimate the outcome model given above. However to calculate the standard 
errors one has to use a panel bootstrap or to estimate the asymptotic variance as described in the Appendix of Wooldridge (1995) and Semykina and Wooldridge (2010), since the model includes estimated right-hand-side variables. Such a model has been estimated by Egger, Loretz, Pfaffermayr, and Winner (2009). Also, Wamser (2011) for bilateral foreign direct investment.

Raymond, Mohnen, Palm, and Schim van der Loeff (2010) propose a maximum-likelihood estimation procedure for a panel random effects sample selection model of the form:

$$
\begin{aligned}
& x_{i j s}=h_{i j s} \gamma+u_{i j}+\varepsilon_{i j s}=A_{i j s}+u_{i j}+\varepsilon_{i j s} \\
& V_{i j t}^{*}=f_{i j s} \delta+k_{i j}+\eta_{i j s}=B_{i j s}+k_{i j}+\eta_{i j s}
\end{aligned}
$$

For the disturbances, they assume

$$
\begin{gathered}
{\left[\begin{array}{l}
u_{i j} \\
k_{i j}
\end{array}\right] \sim N\left(\left[\begin{array}{l}
0 \\
0
\end{array}\right],\left[\begin{array}{cc}
\sigma_{u}^{2} & \rho_{u k} \sigma_{u} \sigma_{\eta} \\
\rho_{u k} \sigma_{u} \sigma_{\eta} & \sigma_{\eta}^{2}
\end{array}\right]\right)} \\
{\left[\begin{array}{c}
\varepsilon_{i s} \\
\eta_{i s}
\end{array}\right] \sim N\left(\left[\begin{array}{l}
0 \\
0
\end{array}\right],\left[\begin{array}{cc}
\sigma_{\varepsilon}^{2} & \rho_{\varepsilon \eta} \sigma_{\varepsilon} \\
\rho_{\varepsilon \eta} \sigma_{\varepsilon} & 1
\end{array}\right]\right) .}
\end{gathered}
$$

Note that $f_{i j s}$ may include $V_{i j 0}$ and $V_{i j s-1}$ to account for initial values and state dependence (see Wooldridge, 2005). The bilateral country pair effects $u_{i j}$ and $k_{i j}$ may be modeled along the lines of Mundlak (1978) as discussed above.

Clearly, the presence of equi-correlation through $u_{i j}$ and $k_{i j}$ would render maximum likelihood estimates inconsistent. Therefore, these effects have to be integrated out. Using the change of variables $v_{i j}=u_{i j} / \sigma_{u}\left(2\left(1-\rho_{u k}^{2}\right)\right)^{1 / 2}$ and $z_{i j}=k_{i j} / \sigma_{k}\left(2\left(1-\rho_{u k}^{2}\right)\right)^{1 / 2}$, so that $d u_{i j}=\sigma_{u}\left(2\left(1-\rho_{u k}^{2}\right)\right)^{1 / 2} d v_{i j}$ and 


$$
\begin{gathered}
d k_{i j}=\sigma_{k}\left(2\left(1-\rho_{u k}^{2}\right)\right)^{1 / 2} d v_{i j} \text {, the likelihood may be written as } \\
\mathcal{L}_{i j}=\int_{-\infty}^{\infty} \int_{-\infty}^{\infty} \prod_{s=1}^{S} L_{i j s} \phi\left(v_{i j}, z_{i j}\right) d v_{i j} d z_{i j}, \\
L_{i j s}=\Phi\left(-B_{i j s}-z_{i j}\right)^{1-V_{i j s}}\left[\frac{1}{\sigma_{\varepsilon}} \phi\left(\frac{x_{i j s}-A_{i j s}-v_{i j}}{\sigma_{\varepsilon}}\right) \times\right. \\
\left.\Phi\left(\frac{B_{i j s}+z_{i j}+\frac{\rho_{\eta}}{\rho_{\varepsilon \eta}}\left(x_{i j s}-A_{i j s}-v_{i j}\right)}{\left(1-\rho_{\varepsilon \eta}\right)^{1 / 2}}\right)\right]^{V_{i j s}},
\end{gathered}
$$

where $\phi\left(u_{i j}, k_{i j}\right)$ denotes the density of the bivariate normal of the random effects. The likelihood can be maximized using numerical optimization procedures. For gravity models, this procedure has been applied by Egger and Pfaffermayr (2011) to estimate effects of dynamic export market entry in general equilibrium.

\subsubsection{Systems of equations}

Many gravity models of bilateral trade lump all goods (and even services) transactions into one sector. This has the advantage that only few parameters have to be estimated, but it involves the problem that those parameters may be inadequate for use at the sectoral level. As a consequence, there could be aggregation error and inadequate out-of-sample predictions. For instance, the same types of goods could be used as final products versus intermediate goods. This might require fundamentally different modeling to describe economic behavior. Similarly, there might be different types of foreign direct investment such as mergers and acquisitions and greenfield investment that might require different modeling. The same arguments might apply to flows of different types of migrants (such as skilled and unskilled one).

Hence, it might be useful to allow the outcome to be determined by type-specific variables which carry type-specific parameters. Moreover, it 
would be desirable to model outcome types to depend on each other. For instance, expenditures on one type of good should not be fully independent of expenditures on another type of good for the same reasons as imports from one country and imports from another country are not independent. Consumers are bound by resource constraints and so are whole countries. Finally, if outcome types are not fully independent of each other, it is logical to allow their shocks to be correlated. All of this suggests that bilateral outcomes could be viewed as systems of equations or, in a structural form, at least as seemingly unrelated regressions.

For instance, Egger and Pfaffermayr (2004a) consider bilateral sectorlevel goods exports and stocks of foreign direct investment in 1989-1999 as seemingly unrelated regressions. The disturbances are allowed to be correlated between exports and foreign direct investment within a sector and year in a reduced-form model, where the two outcomes depend on endogenous bilateral geographical distance in a log-linear way. The stochastic model is a seemingly unrelated regression-type model for two equations, one for $(\log )$ exports and one for (log) outward foreign direct investment. Egger and Pfaffermayr (2004a) find that, indeed, the shocks between exports and foreign direct investment were correlated, in particular, with regard to the time invariant error component. Egger, Larch, and Staub (2012) employ a structural approach for bilateral goods and services trade. In their case, the two outcomes are related to each other for three reasons: they utilize the same factor of production (labor), they are bound by total consumer income, and they face correlated shocks on disturbances. Their model involves structurally restricted exporter-time and importer-time fixed effects and an error component structure regarding the disturbances with a random country-pair term and a random idiosyncratic term. This model represents 
a generalization of the pseudo-maximum likelihood estimation procedure for exponential models with heteroskedastic disturbances as proposed by Santos Silva and Tenreyro (2006) for cross-sectional, single-equation gravity models.

\subsubsection{Dynamics}

Dynamic patterns in bilateral outcome may occur for various reasons. A key factor for rationalizing dynamics are adjustment costs in a broad sense. For instance, such adjustment costs may occur for trade flows due to staggered contracts which will prevent trade flows to respond immediately to technology shocks or trade costs. For stocks or flows of bilateral foreign direct investment adjustment costs can easily be rationalized from a host of investment models. Finally, adjustment costs might matter for migration flows due to information lags about economic circumstances in possible countries of residence. For instance, Eichengreen and Irwin (1998) proposed considering dynamic adjustment when estimating gravity equations.

A log-linear version of a model as in equation (1) with a time lag would $\mathrm{be}^{5}$

$$
\ln X_{i j s}=\delta \ln X_{i j, s-1}+\ln \left(l_{i s} m_{j s} t_{i j s}^{b}\right)+u_{i j s} .
$$

Such a model could be estimated by employing the generalized method of moments procedure for differenced data as proposed by Arellano and Bond (1991) or the systems estimator (which involves both the differenced and the levels equations) proposed by Blundell and Bond (1998). Differenced gravity equations à la Arellano and Bond (1991) are almost never motivated on the basis of a structural model and have been estimated for bilateral

\footnotetext{
${ }^{5}$ An exponential model with a time lag could be estimated, e.g., by a linear backfitting procedure as in Blundell, Griffith, and Windmeijer (2002), or by the control function procedure proposed by Cameron and Trivedi (2005).
} 
trade (see Egger, 2001; Bun and Klaassens, 2002; Millimet and Osang, 2007;

Olivero and Yotov, 2012), for bilateral foreign direct investment (see Egger, 2001; Egger and Pfaffermayr, 2004b; Egger and Merlo, 2011, 2012; or Egger, Loretz, Pfaffermayr, and Winner, 2009), and for bilateral migration (see Mayda, 2010). Systems estimator versions à la Blundell and Bond (1998) have been estimated for bilateral trade flows (see Martínez-Zarzoso, NowakLehmann, and Horsewood, 2009; or Martínez-Zarzoso, Nowak-Lehmann, Klasen, and Larch, 2009), bilateral foreign direct investment (Abbott and De Vita, 2011), and bilateral migration (see Etzo, 2009).

\subsubsection{Endogeneous regressors}

Standard instrumental variables and control function procedures:

Suppose elements of trade costs $t_{i j}$ (with cross-section data) or $t_{i j s}$ (with repeated cross-section data over time) were endogenous. Using the notation given above, this would lead to the endogeneity of $h_{i j}$ with $E\left[e_{i j} \mid h_{i j}\right] \neq 0$ and the endogeneity of $h_{i j s}$ with $E\left[\varepsilon_{i j s} \mid h_{i j s}\right] \neq 0$. Suppose we had instruments $q_{i j}$ with cross sections or $q_{i j s}$ with repeated cross sections over time. With column rank $k$ for $h_{i j}$ and $h_{i j s}$ and column rank $k^{\prime} \geq k$ for $q_{i j}$ and $q_{i j s}$, one could apply standard instrumental-variable estimation or employ a linear or nonlinear (e.g., polynomial) control function of $h_{i j}-\hat{h}_{i j}$ or $h_{i j s}-\hat{h}_{i j s}$ in the outcome equation (see Wooldridge, 2010; Semykina and Wooldridge, 2010). For instance, such a procedure had been applied to gravity models for foreign direct investment by Egger and Merlo (2011, 2012). Egger, Larch, Staub, and Winkelmann (2011) estimated a cross-sectional gravity model on bilateral exports with a mass point at zero and used an instrumental variables procedure in the PPML context to guard against the endogeneity 
of preferential trade agreement membership.

However, no matter whether trade costs are endogenous or not, the variables $l_{i}$ and $m_{j}$ (and the logs thereof) might be endogenous in cross- sectional data. Clearly, $\ln l_{i}$ and $\ln m_{j}$ cannot be estimated if fixed effects $u_{i}$ and $v_{j}$ are included in the model as in Section 3.1. Moreover, $t_{i j s}$ and, hence, $h_{i j s}$ may include time-invariant variables, ${ }^{6}$ so that the parameters of such trade costs (endogenous or not) cannot be identified when fixed effects $u_{i j}$ are included in the model. The subsequent parts of this section address this problem.

\section{Endogenous variables with cross-section data in Hausman and} Taylor type models:

Following Mundlak (1978), Kang (1985), Hausman and Taylor (1981), and Wyhowski (1994), one may include exporter and importer specific means of $h_{i j}$ in a model as in equation (3), if the explanatory variables are supposed to be either correlated with $u_{i}$ or $v_{j}$ or both to obtain the within estimator of $\gamma$. In matrix form, the generalized Mundlak-model for two-way data reads

$$
\begin{aligned}
x & =h \gamma+P_{\left[\Delta_{u}\right]} h \pi_{u}+P_{\left[\Delta_{v}\right]} h \pi_{v}+e \\
e & =\Delta_{u} u+\Delta_{v} v+\varepsilon .
\end{aligned}
$$

A Hausman-Taylor (1981)-type estimation procedure can guard against possible correlation of a subset of the explanatory variables in $h$ with either $u$

\footnotetext{
${ }^{6}$ Notice that the majority of trade cost variables employed in empirical research on gravity models are time invariant. Most variables except for trade agreement membership and bilateral tariffs are of that kind (e.g., geographical variables such as log bilateral distance, contiguity, land accessibility, or cultural variables such as common official language, historical colonial relationships, etc.).
} 
or $v$, but not with $\varepsilon$. For the balanced case, this model has been analyzed by Wyhowski (1994), who specifies

$$
\begin{aligned}
x_{i j} & =\alpha+h_{i j} \gamma+o_{i} \delta+r_{j} \theta+e_{i j}=z_{i j} \phi+e_{i j} \\
e_{i j} & =u_{i}+v_{j}+\varepsilon_{i j}
\end{aligned}
$$

where $o_{i}$ contains variables that vary only in the exporter dimension, while those in $r_{j}$ vary only in the importer dimension. For instance, gross domestic product or per-capita income would be variables of that kind in a gravity context. Wyhowski (1994) introduces the following partition of the set of explanatory variables: $o_{j}=\left[o_{i}^{e}, o_{i}^{u}\right], r_{j}=\left[r_{j}^{e}, r_{j}^{v}\right]$ and $h_{i j}=\left[h_{i j}^{e}, h_{i j}^{u}, h_{i j}^{v}, h_{i j}^{u v}\right]$. Superscript $e$ indicates that the corresponding variables are uncorrelated with the error components and are called doubly exogenous, while superscript $u$ indicates correlation with $u_{i}$ and superscript $v$ correlation with $v_{j}$, respectively. The dimensions of $o_{i}^{e}$ and $o_{i}^{u}$ are $\left(1 \times k_{o e}\right)$ and $\left(1 \times k_{o u}\right)$, respectively. Those of $r_{j}^{e}$ and $r_{j}^{v}$ are $\left(1 \times k_{r e}\right)$ and $\left(1 \times k_{r u}\right)$. Lastly, $h_{i j}^{e}, h_{i j}^{u}$, $h_{i j}^{v}$, and $h_{i j}^{u v}$ are of dimension $\left(1 \times k_{h p}\right)$, where $p \in\{e, u, v, u v\}$. Theorem 1 of Wyhowski (1994) shows that the parameter vector $\phi=\left(\alpha, \gamma^{\prime}, \delta^{\prime}, \theta^{\prime}\right)^{\prime}$ is identified if (i) $k_{h e}+k_{h u} \geq k_{o u}$ and (ii) $k_{h e}+k_{h v} \geq k_{r v}$.

Wyhowski (1994) demonstrates that one obtains consistent parameter estimates if one uses a comprehensive set of instruments with a Hausman and Taylor (1981) type instrumental variables estimator. In the context of gravity models, this procedure has been applied by Egger (2005) to identify the parameters of the potentially endogenous gross domestic product and per-capita income variables in a cross section setting.

Endogenous variables with repeated cross-section (panel) data in Hausman and Taylor type models: 
The lion's share of the variance in log bilateral trade flows $x_{i j s}$ is contributed by the exporter-importer (time-invariant) component (see Baltagi, Egger, and Pfaffermayr, 2003). Hence, there is a particularly big chance for endogeneity of time-variant or time-invariant variables in gravity models to be correlated with the time-invariant part of the error term. Accordingly, if cross sections of country-pairs are observed repeatedly over time, it may be desirable to include country-pair fixed effects to guard against this endogeneity. Clearly, the parameters on most observable measures of trade costs - such as log bilateral distance, common official bilateral language, contiguity, etc. - cannot be identified anymore. The model proposed by Hausman and Taylor (1981) offers a suitable strategy to avoid this problem. It allows a subset of the explanatory variables to be correlated with the bilateral (country-pair) effects, and at the same time provides consistent parameter estimates of the time-invariant variables such as log bilateral distance. Note this model can also be estimated with unbalanced data when data are missing at random. The model can be written as

$$
\begin{aligned}
x_{i j s} & =\alpha+h_{i j s} \gamma+r_{i j} \delta+e_{i j s}=z_{i j s} \phi+e_{i j s} \\
e_{i j s} & =u_{i j}+\varepsilon_{i j s} .
\end{aligned}
$$

Similar to the case with double-indexed cross-sectional data, the set of explanatory variables is partitioned in doubly and singly exogenous variables: $r_{i j}=\left[r_{i j}^{e}, r_{i j}^{u}\right]$ and $h_{i j s}=\left[h_{i j s}^{e}, h_{i j s}^{u}\right]$. Superscript $e$ indicates that the corresponding variables are uncorrelated with either type of error component and are called doubly exogenous, while superscript $u$ indicates correlation of a variable with $u_{i j}$. Both types of variables are assumed to be uncorrelated with the remainder disturbances such that $E\left[r_{i j} e_{i j s}\right]=0$ and $E\left[h_{i j s} e_{i j s}\right]=0$. Hence, the fixed effects (or within-type) estimator $\widetilde{\gamma}_{W}$ which 
wipes out $u_{i j}$ provides a consistent estimator of $\gamma$ but not $\delta$. The dimensions of $r_{i j}^{e}$ and $r_{i j}^{u}$ are $\left(1 \times k_{r e}\right)$ and $\left(1 \times k_{r u}\right)$, respectively, and those of $h_{i j s}^{e}$ and $h_{i j s}^{u}$ are dimension $\left(1 \times k_{h e}\right)$ and $\left(1 \times k_{h u}\right)$, respectively. The parameter vector $\phi=\left(\alpha, \gamma^{\prime}, \delta^{\prime}\right)^{\prime}$ is identified if $k_{h e} \geq k_{r u}$ holds. The Hausman and Taylor (1981) procedure provides a more efficient estimator $\widehat{\gamma}_{H T}$ provided the choice of exogenous variables is correct and the model is over-identified, i.e., $k_{h e}-k_{z u}>0$. This over-identification condition can be tested against the within estimator using a Hausman-type test. In the context of gravity models, this procedure has been first applied by Egger (2004b), illustrating that $\log$ bilateral distance is likely endogenous in gravity models of bilateral trade. The estimator has been generalized in Egger (2002) to account for serial correlation in $e_{i j s}$, and to illustrate properties of so-called export potentials. Moreover, it has been used by Egger and Pfaffermayr (2004b) to quantify the log distance coefficient for exports and foreign direct investment in a system with bilateral exports and foreign direct investment of the United States.

\subsubsection{Cross-sectional interdependence}

Notice that the models discussed in Section 2 generally involve contagious effects of explanatory variables on outcome through general equilibrium. Suppose bilateral trade costs or - for exogenous reasons - the real production or the consumer base of a country change. This will have repercussions on the producer as well as consumer prices of goods or services. This can be seen from the definition of outcome in equation (1), $X_{i j s}=l_{i s} m_{j s} t_{i j s}^{b}$ and the fact that $l_{i s}$ and $m_{j s}$ are endogenous, since

$$
m_{j s} \equiv \frac{Y_{j s}}{\sum_{k=1}^{F} l_{k s} t_{k j s}^{b}}
$$


and, through $\sum_{j=1}^{F} X_{i j s}=Y_{i s}=l_{i s} \sum_{j=1}^{F} m_{j s} t_{i j s}^{b}$. Hence, given (estimates of) $t_{k j s}^{b}$ and data on gross domestic product, $Y_{i s}, l_{i s}$ and $m_{j s}$ are determined as multilateral, triangular functions of those variables.

Of course, accounting for $l_{i s}$ and $m_{j s}$ by fixed $i s$-specific and $j s$-specific effects, respectively, allows taking this cross-sectional correlation into account. In this context, a standard framework with random is-specific and $j s$-specific will be inappropriate not only for reasons of endogeneity (since these effects are functions of $t_{i j s}^{b}$ ), but also since the country-year-specific effects are not independent of each other (i.e., the one for is is correlated with the one for $i^{\prime} s$ for $i^{\prime} \neq i$, and the one for $j s$ is correlated with the one for $j^{\prime} s$ for $j^{\prime} \neq j$ ). Clearly, this makes $X_{i j s}$ dependent on $X_{i^{\prime} j s}$, on $X_{i j^{\prime} s}$, and on $X_{i^{\prime} j^{\prime} s}$ for all $i^{\prime} \neq i$ and $j^{\prime} \neq j$. The source of this cross-sectional interdependence are general equilibrium or resource constraints.

Two other forms of cross-sectional dependence that may possibly play a role are strategic interaction and cross-sectional dependence through unobservable determinants of outcome captured by the disturbances. The former would emerge, for example, if the entry of exporters into a market, that of multinational firms into a market, or that of migrants into a country, would strategically by way of information diffusion depend upon other such units' decisions. A log-linear version of the model in equation (1) with strategic interaction and an additive disturbance $e_{i j(s)}$ would then read

$$
\ln X_{i j(s)}=\lambda\left(\sum_{h \neq i} \sum_{k \neq j} w_{i j, h k(s)} \ln X_{h k(s)}\right)+\ln \left(l_{i(s)} m_{j(s)} t_{i j(s)}^{b}\right)+e_{i j(s)}
$$

where $\lambda$ could be referred to as a spatial lag parameter and $w_{i, h k}$ as a spatial weight (see Anselin, 1988; Kelejian and Prucha, 1999; for the necessary properties of such weights and parameters). Such models have been esti- 
mated for bilateral trade flows (see Lebreton and Roia, 2011), for bilateral foreign direct investment (see Blonigen, Davies, Waddell, and Naughton, 2007; Blonigen, Davies, Naughton, and Waddell, 2008), and for bilateral migration (see LeSage and Pace, 2008).

If contagion surfaces by way of correlation of the disturbances instead, one could reformulate the disturbance term of a cross-sectional gravity model as a spatial autoregressive model of the form

$$
\varepsilon=R \varepsilon+\xi
$$

where $\xi$ is the independently distributed counterpart to $\varepsilon$ and $R$ is an $E F \times$ EF matrix which exhibits zero diagonal elements and has finitely summable row and column elements (see Chapter 5 on spatial panels in this Handbook). A leading example in the literature is

$$
\varepsilon_{i j}=\rho\left(\sum_{h \neq i} \sum_{k \neq j} w_{i j, h k} \varepsilon_{h k}\right)+\xi_{i j},
$$

which is referred to as a first-order spatially autoregressive model, involving known weights $w_{h k}$ and one unknown (spatial autoregressive) parameter $\rho$ (see Kelejian and Prucha, 1999, 2007, for the underlying assumptions). A similar structure could be assumed for $e_{i j}=u_{i}+v_{j}+\varepsilon_{i j}$. Similarly, with repeated cross-section data of bilateral trade over time and stacking the data in an $(E F S \times E F S)$ block-diagonal matrix $R_{S}=\operatorname{diag}(R, \ldots, R)$ the same notation might be used.

Models allowing for an error structure akin to the one in (45) have been estimated for trade flows (see Porojan, 2001; and Behrens, Ertur, and Koch, 2012), ${ }^{7}$ for foreign direct investment (see Coghlin and Segev, 2000; Baltagi,

\footnotetext{
${ }^{7}$ Behrens, Ertur, and Koch (2012), use more theoretical rigor than others to derive a
} 
Egger, and Pfaffermayr, 2007, 2008), and for migration flows (see Bertolia and Fernández-Huertas Moraga, 2012).

From a theoretical perspective, many of the aforementioned applications can build on research which motivates cross-sectional interdependence in flow models between two spatial units, but they commonly lack the rigorous treatment of interdependence as in structural models underlying the generic framework in Section 2. For this reason, spatial lag models as the one in (44) have not found the recognition in empirical international economics. Considering interdependence structures in disturbances may be a fruitful econometric strategy, since it can be combined with structural modeling of the deterministic part, and permit improvements in inference and comparative statics compared to procedures that consider the disturbances to be cross-sectionally independent. Cross-sectional dependence of the disturbances leads to biased standard errors of the parameters $\gamma$ and the comparative static effects based on a structural model as the one in Section 2.1. The latter may be particularly relevant when quantifying trade or welfare effects of changes in trade costs. However, consistent estimates of the standard errors could be obtained by procedures outlined in Kelejian and Prucha (2007). Such procedures have been applied in the context of bilateral trade flow models by Behrens, Ertur, and Koch (2012) and for foreign direct investment by Baltagi, Egger, and Pfaffermayr (2007, 2008).

spatial econometric model which involves weighted bilateral exports of other pairs as a determinant of bilateral exports of a given pair of trading partners. 


\subsubsection{Normalized outcomes}

Head and Ries (2001) proposed transforming the deterministic part of equation (1) in the following way:

$$
\sqrt{\frac{X_{i j s}}{X_{j i s}} \frac{X_{i i s}}{X_{j j s}}}=\sqrt{\frac{t_{i j s}^{b}}{t_{j j s}^{b}} \frac{t_{j i s}^{b}}{t_{i i s}^{b}}}=\sqrt{t_{i j s}^{b} t_{j i s}^{b}} \text { if } t_{i i s}^{b}, t_{j j s}^{b}=1
$$

for all $i, j, s$, and analogously for cross sections. The appeal of this normalization lies in the elimination of all exporter-time and importer-time-specific factors from equation (12). However, this advantage comes at a cost: with cross sections or panels involving a large number of countries, the above normalization aggravates the problem of zeros in the bilateral trade matrix dramatically $;^{8}$ and exporter-time or importer-time-specific trade costs cancel out so that their parameters can not be estimated, akin to models with fixed exporter-time and importer-time effects. ${ }^{9}$

Adding a log-additive error term and transforming the model in logs yields

$$
\ln \frac{X_{i j s}}{X_{j i s}} \frac{X_{i i s}}{X_{j j s}}=0.5\left(h_{i j s}+h_{j i s}\right) \gamma+\left(\varepsilon_{i j s}+\varepsilon_{j i s}-\varepsilon_{i i s}-\varepsilon_{j j s}\right) .
$$

In particular, such a stochastic model is difficult to estimate if the stochastic terms are not independent and there is cross-sectional correlation.

\footnotetext{
${ }^{8}$ In large data-sets $P\left[X_{i j s}>0\right]$ often takes values of 0.3 (especially, in the $1960 \mathrm{~s}$ and earlier) to 0.7 (more recently). Hence, such-transformed data contain about $P\left[X_{i j s}>\right.$ $0]-P\left[\frac{X_{i j s}}{X_{j j s}} \frac{X_{i i s}}{X_{i k s}}>0\right] \approx\left(P\left[X_{i j s}>0\right]\right)^{2}$ - or one-to-two thirds - more zeros than the untransformed data.

${ }^{9}$ In essence, this means that the overall level of fixed costs $t_{i j s}^{b}$ can not be estimated consistently. This is a severe problem, since exporter-time and importer-time-specific fixed costs can be shown to be important, and comparative static effects of changes in observable trade costs are extremely sensitive to large measurement errors about total trade cost levels (see Egger, Larch, and Staub, 2012).
} 
The gravity model could alternatively be transformed to yield a logistic specification in terms of log-odds ratios (see, e.g., Head, Mayer and Ries, 2010). Similar to the two-way within model, the logistic transformation normalizes nominal trade flows so that exporter and importer specific determinants are eliminated but the impact of the bilateral ones still remain identified. The gravity model can be written in terms of relative log-odds or tetradic terms

$$
\ln \frac{X_{i j}}{X_{i k}}-\ln \frac{X_{l j}}{X_{l k}}=\left(h_{i j}-h_{i k}-h_{l j}+h_{l k}\right) \gamma+\left(\varepsilon_{i j}-\varepsilon_{i k}-\varepsilon_{l j}+\varepsilon_{l k}\right) .
$$

where exporter country $l$, importer country $k$ and the bilateral trade flow between them serves as the basis. An advantage of this approach is that the base categories $X_{i k}$ and $X_{l k}$ are readily observed if picking country $k$ properly, while this is not the case with intranational sales $X_{i i s}$ and $X_{j j s}$ employed in the previous approach. With either type of normalization, it may be advisable to use multi-way clustering as proposed by Cameron, Gelbach and Miller (2011); see Head, Mayer and Ries (2010).

\subsubsection{Linearly approximated models}

Baier and Bergstrand (2009) proposed approximating the structural model in Section 2.1 for a cross section of bilateral trade flows as follows. Parameterize $b \ln t_{i j}$ as $h_{i j} \gamma$ and denote the $k$ th elements of $h_{i j}$ and $\gamma$ by $h_{k, i j}$ and $\gamma_{k}$ respectively. Moreover, define $\breve{h}_{k, i .} \equiv \sum_{j=1}^{F} \theta_{j} h_{k, i j}, \breve{h}_{k, . j} \equiv \sum_{i=1}^{E} \theta_{i} h_{k, i j}$, and $\breve{h}_{k, . .} \equiv \sum_{i=1}^{E} \sum_{j=1}^{F} \theta_{i} \theta_{j} h_{k, i j}$ to obtain

$$
\widetilde{h}_{k, i j} \equiv h_{k, i j}-\breve{h}_{k, i .}-\breve{h}_{k, . j}+\breve{h}_{k, . .}
$$


Then, the linearly-approximated model à la Baier and Bergstrand (2009) involves

$$
x_{i j}-\ln \left(Y_{i} Y_{j}\right) \approx \alpha+\widetilde{h}_{i j} \gamma
$$

where $\alpha$ is a constant. To the panel econometrician, the analogy of this approximation to a two-way (quasi-)within transformation of $h_{i j}$ with balanced panels is evident: if $E=F$ and all countries were of identical size, $\theta_{i}, \theta_{j}=1 / F$. Then, $\widetilde{h}_{k, i j} \equiv h_{k, i j}-h_{k, i .}-h_{k, . j}+h_{k, . .}, h_{k, . j}=\frac{1}{F} \sum_{i=1}^{F} h_{k, i j}$, and $h_{k, . .}=\frac{1}{F^{2}} \sum_{i=1}^{F} \sum_{j=1}^{F} h_{k, i j}$. However, the analogy is not perfect, since countries are not identically sized. The weighting by expenditure shares $\left(\theta_{i}\right.$ and $\left.\theta_{j}\right)$ in the transformation for $\widetilde{h}_{k, i j}$ does not fully eliminate country-specific trade costs (which is an advantage).

As long as the income constraints matter for each time period separately, the model can be readily adapted with panel data, involving

$$
\widetilde{h}_{k, i j s} \equiv h_{k, i j s}-\breve{h}_{k, i . s}-\breve{h}_{k, . j s}+\breve{h}_{k, . . s}
$$

which are just period-specific transformations, so that one obtains

$$
x_{i j s}-\ln \left(Y_{i s} Y_{j s}\right) \approx \alpha_{s}+\widetilde{h}_{i j s} \gamma
$$

where $\alpha_{s}$ is a time-specific constant. Baier and Bergstrand (2009) applied this approximation with cross section data, and Carrère (2006) and Egger and Nelson (2011) applied it with panel data.

However, the replacement of $\ln \left(l_{i} m_{j} t_{i j}^{b}\right)$ by $\widetilde{\ln t_{i j}^{b}}$ has further consequences. For instance, binary and other discrete variables in $h_{i j}$ (such as regional trade agreement membership indicators or trade freedom or political freedom indices) are transformed into continuous (bounded) variables. In case of endogeneity, proper methods have to be used to avoid the endogeneity bias. 
For instance, with a control function approach, the residuals from a firststage model have to be transformed analogously to $h_{k, i j}$ in $\widetilde{h}_{k, i j}$. Moreover, notice that the approximation error is a (nonlinear) function of the variables in the model (all countries' $\theta_{i}$ and $h_{k, i j}$ for bilateral trade of a given pair $i j$ ). The latter involves both heteroskedasticity as well as cross-sectional dependence in the disturbances.

\subsubsection{Interpretation of disturbances}

There are three main strands of interpretation of the disturbances $e_{i j}$ in the literature. Some authors (implicitly) assume that $e_{i j}$ contains an unmeasured part of true trade costs (see the definition of trade costs in equation (29) in Eaton and Kortum (2002), and the discussion between equations (29) and (30), there). In that case, true trade costs are $t_{i j}^{b} \exp u_{i j}$ rather than $t_{i j}^{b}$. Others assume that true trade costs are $t_{i j}^{b}$ but what is measured is $t_{i j}^{b} \exp e_{i j}$, implying the existence of measurement error. Finally, some authors assume that $e_{i j}$ is simply a measurement error for $X_{i j}$. Obviously, the last interpretation is unproblematic. The second interpretation requires methods for modeling measurement error to avoid an associated (endogeneity) bias. The first interpretation - which is also one of measurement error - is most difficult to deal with, since the constraint about the importer-time effect mentioned in Section 2 now reads $m_{j s} \equiv \frac{Y_{j s}}{\sum_{k=1}^{E} l_{k s} t_{k j s}^{b} \exp \left(e_{k j s}\right)}$. Such a measurement error can be addressed using the fact that aggregate bilateral demand adds up to gross domestic product, $Y_{i}=\sum_{j=1}^{F} X_{i j}$, and export shares as well as import shares add up to unity, i.e., $\sum_{j=1}^{F}\left(X_{i j} / Y_{i}\right)=1$ (see Eaton, Kortum, and Sotelo, 2012). 


\subsection{Specific topics}

\subsubsection{Fixed effects versus random effects}

The use of fixed effects by way of binary indicator variables is quite established in gravity modeling. Pöyhönen (1963) was probably the first to control for country-specific fixed effects in cross-sectional data. The use of fixed country effects is now viewed as an acceptable procedure in structural modeling of trade flows (see Feenstra, 2002; Eaton and Kortum, 2002; Anderson and van Wincoop, 2003; Egger and Larch, 2012; Bergstrand, Egger, and Larch, 2013). In general, an appeal for using fixed effects is that the parameters on the regressors which are not fully collinear with the fixed effects can be estimated with less danger of an endogeneity bias. However, this advantage comes at a potentially high cost of efficiency loss. In cross-sectional models, the use of country-specific fixed effects is largely unproblematic, since the number of observations tends to be not much short of $(E-1)(F-1)$ (typically, intra-national sales are not included in the data; and missing data may lead to a further loss of observations) while the number of fixed effects estimated is only $E+F$. With triple-indexed models and repeated observations of country-pairs over time, one gets up to $(E-1)(F-1) S$ observations (with the number of time periods $S$ being relatively small) and $(E-1)(F-1)$ fixed country-pair effects as well as $(E-1) S$ and $(F-1) S$ exporter-time and importer-time effects respectively..

Clearly, with repeated observations of country-pairs' bilateral trade flows over time and a triple-indexed aggregate gravity equation, there are many options for modeling fixed effects. One version would be to include main effects only, namely, exporting country, importing country, and time effects. Such a model has been proposed by Mátyás $(1997,1998)$. The most general 
version is one which includes exporter-time, importer-time, and countrypair (exporter-importer) effects. ${ }^{10}$ This general version has been proposed by Baltagi, Egger, and Pfaffermayr (2003). Any triple-indexed model with fewer effects than the one of Baltagi, Egger, and Pfaffermayr (2003) can be thought of as a restricted version of this general framework, and it can be tested against it. Models with separate country-pair and common time effects are quite prominent in the literature. For instance, Baldwin (1994) used such a framework to estimate effects of economic integration, assuming that the country-pair effects were random. Usually, gravity models with random country-pair effects are only estimated for comparison with fixed effects models (see Egger, 2000, 2002, 2004a,b; Egger and Pfaffermayr, 2003). Egger and Pfaffermayr (2003) discussed models with fixed (exporter, importer, and year) main effects and fixed versus random exporter-importer interaction (i,.e., country-pair) effects to test the pair effects model against the country effects model. They find that pair effects should not be ignored. Models with fixed country-pair effects have been estimated by Egger and Pfaffermayr (2004b), Baltagi, Egger, and Pfaffermayr (2008), Egger, Loretz, Pfaffermayr, and Winner (2009). Egger and Merlo (2011, 2012) used models with fixed country-pair effects for foreign direct investment, and Orefice (2013) estimated models involving country-pair effects on migration. Other articles ignore the country-pair equi-correlation in the disturbances altogether and condition on country-time effects. For the data generating

\footnotetext{
${ }^{10}$ In general, one could think of dyadic pair effects where the fixed effect for pair $i j$ would be forced to be identical to the one for pair $j i$. However, unless the data themselves are symmetric (e.g., because bilateral exports plus imports are used as a dependent variable, which is not advisable, see Baldwin and Taglioni, 2005), this restriction is unlikely to be justified.
} 
process outlined in Section 2.1, country-time effects are implicit functions of bilateral transaction costs.

Empirically, country-pair effects explain much more of the variation in bilateral exports or imports, foreign direct investment, or migration than country-time effects. This implies a relatively big chance for omitted countrypair-specific effects to induce endogeneity of pair-specific time-invariant variables (such as bilateral distance, adjacency, common language, etc.) or even of pair-time-specific covariates (such as trade agreement membership, bilateral tariffs, or other measures of preferentialism). The endogeneity of time-invariant trade cost measures such as (log) bilateral distance has been documented in Egger (2004a) and Egger and Pfaffermayr (2004a) for both bilateral trade and foreign direct investment. Common language and other historical, institutional, and legal time-invariant characteristics are endogenous. The reason is that common culture is a multi-faceted driver of trade and the measured characteristics typically included in gravity models of bilateral goods trade or other outcomes measure only a small fraction of the universe of time-invariant determinants of bilateral trade (see Egger and Lassmann, 2012). Moreover, the endogeneity of preferentialism has been documented for goods trade, services trade, and foreign direct investment (see Egger and Pfaffermayr, 2004b; Egger, Egger, and Greenaway, 2008; Baier and Bergstrand, 2007; Egger, Larch, Staub, and Winkelmann, 2011; Egger and Wamser 2013a,b). Clearly, with endogenous triple-indexed variables in triple-indexed models one has to rely on nonparametric identification by relying on selection on observables or on outside instruments (through control functions or instrumental variables estimation).

However, double-indexed (or, generally, single-indexed) endogenous variables (such as log bilateral distance, common language, etc.) can be instru- 
mented from within the triple-indexed (or, generally, higher-indexed) model by splitting all higher-indexed variables into two (or, if necessary, more) dimensions of the data and eventually using them as separate variables for instrumentation. Related work follows the idea of Hausman and Taylor (1981), Amemiya and MaCurdy (1986), Breusch, Mizon, and Schmidt (1989), Cornwell, Schmidt, and Wyhowski (1992), and Wyhowski (1994) to discern exogenous single-indexed and endogenous single-indexed variables on the one hand and fully exogenous all-indexed and partly exogenous allindexed variables on the other hand. For instance, Egger (2004b) considers log bilateral distance as an endogenous single-indexed variable (because it is time-invariant and the country-pair index is used as a single crosssectional index) and time-plus-country-pair-indexed variables as covariates in a non-structural gravity equation of bilateral exports. All of the timevariant variables are assumed to be uncorrelated with the time-variant error component. But some of them are fully exogenous (also uncorrelated with the time-invariant error component) and some of them are partly exogenous (correlated with the time-invariant error component). For identification, there must be at least as many doubly exogenous all-indexed variables as there are endogenous single-indexed ones in the model. Then, the respective single-indexed component of all-indexed doubly exogenous variables can be used as an instrument for endogenous single-indexed variables in the model (which log distance is the example of in Egger, 2004b, and Egger and Pfaffermayr, 2004b). The papers by Egger (2004) and Egger and Pfaffermayr (2004b) show that the coefficient of the instrumented log distance is largely different from the one of a random (country-pair) effects model or a pooled OLS model. Serlenga and Shin (2007) apply this strategy to gravity models of bilateral goods trade in the context of European economic integration. 
A general conclusion from that literature is that the distance coefficient in cross-sectional gravity models of bilateral goods trade or bilateral foreign direct investment is likely biased, and the bias is probably large. Similar conclusions might hold for other coefficients on time-invariant geographical or institutional variables.

\subsubsection{Effects of preferential agreements on outcome}

A large literature in trade analyzes the effects of a country's membership in trade agreements on trade flows. Similar literature assess the impact of services trade agreements on services flows, and of investment (or tax) agreements on foreign direct investment. Since the 1950s, hundreds of goods trade agreements have been notified and most of them are now governed by the World Trade Organization. Similarly, a huge number of bilateral investment treaties, tax treaties, and services trade agreements have been signed by now. Egger and Wamser $(2013 \mathrm{a}, \mathrm{b})$ provide a broad overview of the theoretical and empirical literature on preferentialism. Most of the studies on the effects of preferential agreements assess the impact of bilateral goods trade agreement membership on bilateral goods trade, but more recent work considers agreements and outcomes beyond goods trade. While earlier research focused on cross-sectional data, more recent studies exploit the time variation in the data. Studies of the latter kind typically employ countrypair fixed effects by way of a within transformation in static models or by estimating dynamic differenced models.

An overwhelming number of studies analyzed preferential agreement effects (in particular, those of goods trade agreements) in cross sections of country-pairs. A key problem of such a strategy is the potential endo- 
geneity of preferential agreement membership. In cross sectional data, this endogeneity is typically not overcome in a two-way fixed effects framework with exporter and importer country fixed effects. Then, instrumental variable strategies, switching regression, or other strategies based on selection on observables should be employed. For instance, Baier and Bergstrand (2007) propose matching on the propensity score which is estimated from a bilateral trade agreement membership model in cross-sectional bilateral trade data. Egger, Larch, Staub, and Winkelmann (2011) develop a model where, in a cross-section, country-specific effects are controlled for by exporter and importer-specific fixed effects. Trade agreements are allowed to be endogenous in a two-part model to account for zero trade flows.

More recent work tends to favor the identification of preferential agreements from time series of country-pairs. For instance, using pooled data points on country-pairs' trade for every fifth year between 1960 and 2000, Baier and Bergstrand (2007) find that the bias from self-selection of country pairs into trade agreements may be substantially reduced when employing pair-specific fixed effects. Egger, Larch, and Staub (2012) estimate the impact of goods and services trade memberships on trade flows (and welfare), employing fixed country-time effects using annual panel data covering the period 1996-2005. Egger (2001) and Martínez-Zarzoso, Nowak-Lehmann, and Horsewood (2009), among others, difference out fixed country-pair effects (and allow for partial adjustment). However, the finding that the selection bias of preferential (trade) agreement membership can be avoided by conditioning on country-pair effects seems to depend on the data at hand. For instance, Egger and Wamser (2013b) find that a nonparametric framework of selection on observables still results in estimates of the effect of preferential agreements (goods or services trade agreements, bilateral investment 
treaties, or double taxation treaties) on bilateral trade flows. The latter suggests that the parameter bias on preferential agreement indicators accruing to self selection is not fully overcome by removing the within variation in the data. Egger, Egger, and Greenaway (2008) proposed combining a selectionon-observables identification strategy with a difference-in-difference model for switching into preferential agreements. In this model, the selection bias is not fully removed from differencing the data.

Baltagi, Egger, and Pfaffermayr (2003) proposed a more general framework for estimating panel data gravity models which employs country-pair, exporter-year, and importer-year fixed effects. Such a model explains almost all of the variation in data on bilateral exports or imports. As long as the fixed effects do not wipe out all of the variation of interest, it will likely remove most sources of inconsistency. Cross-sectional fixed (exporter and importer) country effects models which involve the traditional pair-specific trade cost variables (log distance, common border, common language, preferential trade agreement membership, etc.) can explain about $60-80 \%$ of the variation in the data on bilateral trade (see Bergstrand, Egger, and Larch, 2013). Panel data models with country-pair, exporter-time, and importertime fixed effects explain 95-98\% of the variation in the data (see Baltagi, Egger and Pfaffermayr, 2003). When imposing proper constraints, such a model even has a structural interpretation and can be used for general equilibrium comparative static analysis (see Egger and Nigai, 2013).

A variant of a model with fixed pair and fixed country-time effects has been proposed by Egger and Pfaffermayr (2013) to assess the effect of the formation of the European Union on bilateral trade flows. Rather than imposing country-year fixed effects, they introduce country blocs. These are associated with groups of countries that entered the European Union until 
2001 at a time (six founding countries; three entrants in 1973, one entrant in 1981, two in 1986, three in 1995 - and one outside group) and the phases of a particular size of the Union (1960-1964; 1965-1972; 1973-1980; 1981-1985; 1986-1994; 1995-2001). They follow intra-bloc and inter-bloc trade for all six blocs over the six phases since 1960 which permits them to focus on trade creation and trade diversion effects of European integration. In a somewhat more restrictive framework regarding the functional form assumptions of integration effects, but with the appeal of structural (general equilibrium) interpretation, this approach was applied in Carrère (2006), Egger and Larch (2011), and Egger and Nelson (2011). ${ }^{11}$

\subsubsection{Potential outcomes}

An old interest in estimating gravity models relates to the issue of so-called trade (or foreign direct investment) potentials (see Baldwin, 1993, 1994; Gros and Gonciarz, 1996; Brenton and DiMauro, 1998; Nilsson, 2000; De Benedictis and Vicarelli, 2005). In essence, this literature is about comparing model predictions about bilateral outcome, $\hat{X}_{i j(s)}$, to the data on

outcome, $X_{i j(s)}$. Depending on whether $\hat{X}_{i j(s)}>X_{i j(s)}$ or $\hat{X}_{i j(s)}<X_{i j(s)}$, country-pairs are said to under- or over-exhaust their (trade or foreign direct investment) potentials (at time $s$, if the data carry a time index). One root of that literature is policy advice surrounding the question which funding lines and country initiatives should be prioritized to stimulate trade or

\footnotetext{
${ }^{11}$ Models with time effects that vary in the cross section but not quite across countries are often used for a different reason than in Egger and Pfaffermayr (2013), namely with non-linear models or in large samples to reduce the amount of fixed effects to be estimated. For that reason, e.g., Egger and Wamser (2013b) employ fixed country-pair effects along with fixed exporter-continent-time and importer-continent-time effects.
} 
foreign direct investment.

Clearly, this line of research faces a number of problems. First, if models are estimated on log-transformed data but potentials are calculated on bilateral outcome in levels, the predictions tend to under-predict the data because the log-transformation does not work well if the variance in the data is large, as is typically the case (Jensen's inequality; see Egger, 2010). Second, even in the absence of this problem it is the case that, e.g.,

$E\left[F^{-1} \sum_{j=1}^{F}\left(X_{i j(s)}-\hat{X}_{i j(s)}\right)\right] \neq 0$ if $\left[F^{-1} \sum_{j=1}^{F}\left(\ln X_{i j(s)}-\ln \hat{X}_{i j(s)}\right)\right] \neq 0$ is an indication of model mis-specification (see Egger, 2002). Clearly, with fixed country(-time) effects what is referred to as the country-specific difference between potential and actual outcome is absorbed in the fixed effects. Similarly, for the average year, that difference would be absorbed in a model with country-pair fixed effects. Overall, this leaves little meaningful scope for the literature on un-exhausted potentials.

\subsubsection{Non-structural versus structural estimates}

With non-structural estimates, we have to distinguish between two types. First, suppose the researcher estimates a log-linear model of the form

$$
x_{i j(s)}=\alpha_{(s)}+\zeta_{1} \ln Y_{i s}+\zeta_{2} Y_{j(s)}+\zeta_{3} \ln L_{i(s)}+\zeta_{4} L_{j(s)}+h_{i j(s)} \gamma+e_{i j(s)}
$$

where $\ln Y_{i s}$ and $\ln L_{i(s)}$ measure the $\log$ gross domestic income and $\log$ population size of country $i$ (in year $s$ ), respectively. Clearly, this is a simple re-parametrization of a model which employs per-capita incomes $\left(\ln \left(Y_{i(s)} / L(i(s))\right)\right.$ instead of $\ln L_{i(s)}$. As long as no country(-time) fixed effects are included, this model will generate biased parameters if the structural model in Section 2 applies. The reason is simply that $\ln l_{i(s)}$ and $\ln m_{j(s)}$ are non(log-)linear functions of $Y_{i^{\prime}(s)}$ and $h_{i^{\prime} j^{\prime}(s)}$ for all $i^{\prime} j^{\prime}$ in the model. The 
latter generates both endogeneity as well as heteroskedasticity in the above ad-hoc reduced-form model versions that have been estimated for decades to date. ${ }^{12}$

A second type of nonstructural model

$$
x_{i j(s)}=h_{i j(s)} \gamma+u_{i j}+v_{i(s)}+w_{j(s)}+\varepsilon_{i j(s)}
$$

is estimated with $v_{i(s)}$ and $w_{j(s)}$ denoting fixed country(-time) effects for exporters and importers, respectively. This model obtains consistent estimates of $\gamma$. Given $\hat{\gamma}$ and, hence, $t_{i j(s)}^{b}$ and expenditures/income $Y_{i s}$ for all countries $i$ and $j$, one may solve for $\hat{l}_{i(s)}$ and $\hat{m}_{j(s)}$ as introduced in Section 2.1. In empirical data-sets, $\hat{l}_{i(s)}$ and $\hat{m}_{j(s)}$ will not be identical to $v_{i(s)}$ and $w_{j(s)}$ for reasons discussed in Egger, Larch, and Staub (2012). The latter means that the center of the predictions of the structural model

$$
\hat{X}_{i j(s)}=\exp \left(h_{i j(s)} \hat{\gamma}+\hat{l}_{i(s)}+\hat{m}_{j(s)}\right)
$$

will not necessarily lie in the center of the data, unlike those of a PPML model of the form

$$
\hat{X}_{i j(s)}=\exp \left(h_{i j(s)} \hat{\gamma}+\hat{u}_{i j}+\hat{v}_{i(s)}+\hat{w}_{j(s)}\right)
$$

One consequence of the latter is that the structural model predictions based on trade cost estimates in fixed country effects models will predict structural model solutions that may be largely different from the actual data (see Bergstrand, Egger, and Larch, 2013). Only an iterative structural model or a constrained fixed effects model as in Egger, Larch, and Staub (2012) will close the gap between fixed effects estimation and structural model

\footnotetext{
${ }^{12}$ This argument holds true whether a log-linear model, a PPML, or a nonlinear leastsquares exponential model is estimated.
} 
estimation with cross-sections or repeated cross-sections of bilateral trade flows in gravity models.

\section{References}

Abbott, Andrew J. and De Vita, Glauco, 2011. Evidence on the impact of exchange rate regimes on bilateral FDI flows. Journal of Economic Studies 38(3-4), 253-274.

Amemiya Takeshi and Thomas E. MaCurdy, 1986. Instrumental-variable estimation of an error-components Model. Econometrica 54(4), 869-880.

Anderson, James E., 1979. A theoretical foundation for the gravity equation. American Economic Review 69(1), 106-116.

Anderson, James E., 2011. The gravity model. Annual Review of Economics 3(1), 133-160.

Anderson, James E. and Eric van Wincoop, 2003. Gravity with gravitas: A solution to the border puzzle. American Economic Review 93(1), 170-192.

Anselin, Luc, 1988. Spatial econometrics: Methods and models. London and Dordrecht: Kluwer Academic Publishers.

Arellano, Manuel, 1987. Computing robust standard errors for within-groups estimators. Oxford Bulletin of Economics and Statistics 49(4), 431-434.

Arellano Manuel and Eric Bond, 1991. Some tests of specification for panel data: Monte carlo evidence and an application to employment. Review of Economic Studies $58(2), 277-297$.

Baier, Scott L. and Jeffrey H. Bergstrand, 2007. Do free trade agreements actually increase members' international trade? Journal of International Economics 71(1), 
$72-95$.

Baier, Scott L. and Jeffrey H. Bergstrand, 2009. Bonus vetus OLS: A simple method for approximating international trade-cost effects using the gravity equation. Journal of International Economics 77(1), 77-85.

Baier, Scott L., Jeffrey H. Bergstrand, and Mitch Gainer, 2012. Structural gravity for foreign direct investment. Unpublished manuscript. University of Notre Dame.

Baldwin, Richard E., 1993. The potential for trade between the countries of EFTA and Central and Eastern Europe. CEPR Discussion Papers no. 853, Centre for Economic Policy Research (CEPR), London.

Baldwin, Richard E., 1994. Towards an Integrated Europe. Centre for Economic Policy Research (CEPR), London.

Baltagi, Badi H., 2008. Econometric Analysis of Panel Data. 4th edition. Chichester: Wiley \& Sons.

Baltagi, Badi H., Peter H. Egger, and Michael Pfaffermayr, 2003. A generalized design for bilateral trade flow models. Economics Letters 80(3), 391-397.

Baltagi, Badi H., Peter H. Egger, and Michael Pfaffermayr, 2007. Estimating models of complex FDI: Are there third-country effects? Journal of Econometrics 140(1) $260-281$

Baltagi, Badi H., Peter H. Egger, and Michael Pfaffermayr, 2008. Estimating regional trade agreement effects on FDI in an interdependent world. Journal of Econometrics 145(1-2), 194-208.

Behrens, Kristian, Cem Ertur, and Wilfried Koch, 2012. 'Dual' gravity: Using spatial econometrics to control for multilateral resistance. Journal of Applied Econometrics 
$27(5), 773-794$.

Bergstrand, Jeffrey H., 1989. The generalized gravity equation, monopolistic competition, and the factor-proportions theory in international trade. Review of Economics and Statistics 71(1), 143-153.

Bergstrand, Jeffrey H., Peter H. Egger, and Mario Larch, 2013. Gravity redux: Estimation of gravity-equation coefficients, elasticities of substitution, and general equilibrium comparative statics under asymmetric bilateral trade costs. Journal of International Economics 89(1), 110-121.

Bertolia, Simone and Jesúus Fernández-Huertas Moraga, 2012. Multilateral resistance to migration. Unpublished manuscript, Fundación de Estudios de Economía Aplicada (FEDEA).

Blonigen, Bruce A., Ronald B. Davies, Helen T. Naughton, and Glen R. Waddell, 2008. Spacey parents: Spatial autoregressive patterns in inbound FDI. in S. Brakman and H. Garretsen (eds.), Foreign Direct Investment and the Multinational Enterprise. Cambridge, MA: MIT Press, 173-198.

Blonigen, Bruce A., Ronald B. Davies, Glen R. Waddell, and Helen T. Naughton, 2007. FDI in space: Spatial autoregressive relationships in foreign direct investment. European Economic Review 51(5), 1303-1325.

Blundell, Richard and Stephen Bond, 1998. Initial conditions and moment restrictions in dynamic panel data models. Journal of Econometrics 87(1), 115-143.

Blundell, Richard, Rachel Griffith, and Frank Windmeijer, 2002. Individual effects and dynamics in count data models. Journal of Econometrics 108(1), 113-131.

Brenton Paul and Francesca DiMauro, 1998. Is there any potential in trade in sensitive 
industrial products between the CEECs and the EU? World Economy 21(3), 285304.

Breusch, Trevor S., Grayham E. Mizon and Peter Schmidt, 1989. Efficient estimation using panel data. Econometrica 57(3), 695-700.

Bun, Maurice J.G., and Franc J.G.M. Klaasen, 2002. The importance of dynamics in panel gravity models of trade, mimeo.

Cameron, Colin A. and Pravin K. Trivedi, 2005. Microeconometrics, Methods and Applications. Cambridge: Cambridge University Press.

Cameron, Colin A., J.B. Gelbach, and D.L. Miller, 2011. Robust inference with multiway clustering. Journal of Business \& Economic Statistics 29(2), 238-249.

Carrère, Céline. 2006. Revisiting the effects of regional trade agreements on trade flows with proper specification of the gravity model. European Economic Review 50(2), 223-247.

Chamberlain, Gary 1982. Multivariate regression models for panel data. Journal of Econometrics 18(1), 5-46.

Coghlin, Cletus C. and Eran Segev, 2000. Foreign direct investment in China: A spatial econometric study. World Economy 23(1), 1-23.

Cornwell, Christopher, Peter Schmidt and Donald Wyhowski, 1992. Simultaneous equations and panel data. Journal of Econometrics, January-February 51(1-2), 151-181.

Davis, Peter., 2002. Estimating multi-way error components models with unbalanced data structures. Journal of Econometrics 106(1), 67-95.

De Benedictis, Luca and Claudio Vicarelli, 2005. Trade potentials in gravity panel data models. Topics in Economic Analysis and Policy 5(1), 1386-1386. 
Docquier, Frédéric, Hillel Rapoport, and Sara Salomone (2010), Remittances and skills. Evidence from bilateral data. Unpublished manuscript. Bar Ilan-University.

Dustmann, Christian and M.E. Rochina-Barrachina, 2007. Selection correction in panel data models: An application to the estimation of females' wage. Econometrics Journal 10(2), 263-293.

Eaton, Jonathan and Samuel S. Kortum, 2002. Technology, geography, and trade. Econometrica 70(5), 1741-1779.

Eaton, Jonathan, Samuel S. Kortum, and Sebastian Sotelo, 2012. International trade: Linking micro and macro. NBER Working Paper no. 17864.

Eaton, Jonathan and Akiko Tamura, 1994. Bilateralism and regionalism in Japanese and U.S. trade and direct foreign investment patterns. Journal of the Japanese and International Economies 8(4), 478-510.

Egger, Hartmut, Egger, Peter H. and David Greenaway, 2008. The trade structure effects of endogenous regional trade Agreements. Journal of International Economics 74(2), 278-298.

Egger, Peter H., 2000. A note on the proper econometric specification of the gravity equation. Economics Letters 66(1), 25-31.

Egger, Peter H., 2001. European exports and outward foreign direct investment: A dynamic panel data approach. Review of World Economics (Weltwirtschaftliches Archiv) 137(3), 427-449.

Egger, Peter H., 2002. An econometric view on the estimation of gravity models and the calculation of trade potentials. World Economy 25(2), 297-312. 
Egger, Peter H., 2004a. Estimating trading bloc effects with panel data. Review of World Economics/Weltwirtschaftliches Archiv 140(1), 151-166.

Egger, Peter H., 2004b. On the problem of endogenous unobserved effects in the estimation of gravity models. Journal of Economic Integration 19(2), 182-191.

Egger, Peter H., 2005. Alternative techniques for estimation of cross-section gravity models. Review of International Economics 13(5), 881-891.

Egger, Peter H., 2010. Bilateral FDI potentials for Austria. Empirica 37(1), 5-17.

Egger, Peter H. and Mario Larch, 2011. An assessment of the Europe agreements' effects on bilateral trade, GDP, and welfare. European Economic Review 55(2), 263-279.

Egger, Peter H. and Mario Larch, 2012. Estimating consistent border effects in gravity models with multilateral resistance. World Economy 35(9), 1121-1125.

Egger, Peter H., Mario Larch, and Kevin E. Staub, 2012. Trade preferences and bilateral trade in goods and services: A structural approach. CEPR Discussion Papers no. 9051, London: C.E.P.R.

Egger, Peter H., Mario Larch, Kevin Staub, and Rainer Winkelmann, 2011. The trade effects of endogenous preferential trade agreements. American Economic Journal: Economic Policy 3(3), 113-143.

Egger, Peter H. and Andrea Lassmann, 2012. The language effect in international trade: A meta-analysis. Economics Letters 116(2), 221-224.

Egger, Peter H., Simon Loretz, Michael Pfaffermayr, and Hannes Winner, 2009. Bilateral effective tax rates and foreign direct investment. International Tax and Public Finance 16(6), 2009, 822-849. 
Egger, Peter H. and Valeria Merlo, 2011. Statutory corporate tax rates and doubletaxation treaties as determinants of multinational firm activity, Finanzarchiv $67(2)$, 145-170.

Egger, Peter H. and Valeria Merlo, 2012. BITs bite: An anatomy of the impact of bilateral investment treaties on multinational firms. Scandinavian Journal of Economics 114(4), 1240-1266.

Egger, Peter H. and Douglas R. Nelson, 2011. How bad is antidumping? Evidence from panel data. Review of Economics and Statistics 93(4), 1374-1390.

Egger, Peter H. and Sergey Nigai, 2013. Structural constrained ANOVA-type estimation of gravity panel data models. Unpublished manuscript, ETH Zurich.

Egger, Peter H. and Michael Pfaffermayr, 2003. The proper panel econometric specification of the gravity equation: A three-way model with bilateral interaction effects. Empirical Economics 28(3), 571-580.

Egger, Peter H. and Michael Pfaffermayr, 2004a. Distance, trade and FDI: A HausmanTaylor SUR approach. Journal of Applied Econometrics 19(2), 227-246.

Egger, Peter H. and Michael Pfaffermayr, 2004b. Foreign direct investment and European integration in the 90s. World Economy 27(1), 99-110.

Egger, Peter H. and Michael Pfaffermayr, 2011. Structural estimation of gravity models with path-dependent market entry. CEPR Discussion Papers 8458, London: Centre for Economic Policy Research.

Egger, Peter H. and Michael Pfaffermayr, 2013. The pure effects of European integration on intra-EU trade. World Economy 36(6), 701â€"-712. 
Egger, Peter H. and Georg Wamser, 2013a. Multiple faces of preferential market access: Their causes and consequences. Economic Policy 28(73), 145-187.

Egger, Peter H. and Georg Wamser, 2013b. Effects of the endogenous scope of preferentialism on international goods trade. CESifo Working Paper no. 4208.

Eichengreen, Barry, and Douglas A. Irwin (1998) The role of history in bilateral trade flows, in The Regionalization of the World Economy, ed. J.A.Frankel (Chicago: University of Chicago Press).

Etzo, Ivan, 2009. The end of the "Empirical Puzzle" and the determinants of interregional migration in Italy: A panel data analysis. Unpublished manuscript, Università degli Studi di Cagliari.

Fally, Thibault, 2012. Structural gravity and fixed effects. Unpublished manuscript, University of Colorado.

Feenstra, Robert C., 2002. Border effects and the gravity equation. Consistent methods for estimation. Scottish Journal of Political Economy 49(5), 491-506.

Gros, Daniel and Andrzej Gonciarz, 1996. A note on the trade potential of Central and Eastern Europe. European Journal of Political Economy 12(4), 709-721.

Glick, Reuven and Andrew Rose, 2002. Does a currency union affect trade? The timeseries evidence. European Economic Review 46(6), 1125-1151.

Hausman, Jerry A. and William E. Taylor, 1981. Panel data and unobservable individual effects. Econometrica 49(6), 1377-1398.

Head, Keith and Thierry Mayer, 2011. Gravity, market potential and economic development. Journal of Economic Geography 11(2), 281-294. 
Head, Keith, Thierry Mayer, and John Ries, 2010. The erosion of colonial trade linkages after independence. Journal of International Economics 81(1), 1-14.

Head, Keith and John Ries, 2001. Increasing returns versus national product differentiation as an explanation for the pattern of US-Canada trade. American Economic Review 91(4), 858-876.

Helpman, Elhanan, Marc Melitz, and Yona Rubinstein, 2008. Estimating trade flows: Trading partners and trading volumes. Quarterly Journal of Economics 123(2), 441-487.

Kang, S., 1985. A note on the equivalence of specification tests in the two-factor multivariate variance components model. Journal of Econometrics 28(2), 193-203.

Kelejian, Harry H. and Ingmar R. Prucha, 1999. A generalized moments estimator for the autoregresssive parameter in a spatial model. International Economic Review 40(2), 509-533.

Kelejian, Harry H. and Ingmar R. Prucha, 2007. HAC estimation in a spatial framework. Journal of Econometrics 140(1), 131-154.

Krugman, Paul 1980. Scale economies, product differentiation, and the pattern of tradeFull. American Economic Review 70(5), 950-959.

Lebreton, Marie and Laïsa Roia, 2009. A spatial interaction model with spatial dependence for trade flows in Oceania: A preliminary analysis. Unpublished manuscript, Université Montesquieu Bordeaux IV.

Leamer, Edward E. and James Levinsohn, 1995. International trade theory: The evidence. In: G. M. Grossman and K. Rogoff (eds.), Handbook of International Economics, edition 1, volume 3, chapter 26, 1339-1394. 
LeSage, James P. and R. Kelley Pace, 2008. Spatial econometric modeling of origindestination flows. Journal of Regional Science 48(5), 941-967.

Levchenko, Andrei and Jing Zhang, 2012. Comparative advantage and the welfare impact of European integration. Economic Policy 27(72), 567-602.

Martínez-Zarzoso, Immaculada, Felicitas Nowak-Lehmann, and Nicolas Horsewood, 2009. Are regional trading agreements beneficial? Static and dynamic gravity models, North American Journal of Economics and Finance 20(1), 46-65.

Martínez-Zarzoso, Immaculada, Felicitas Nowak-Lehmann, Stephan Klasen, and Mario Larch (2009), Does German development aid promote German exports? German Economic Review 10(3), 317-338.

Mátyás, László, 1997. Proper econometric specification of the gravity model. World Economy 20(3), 363-368.

Mátyás, László, 1998. The gravity model: Some econometric considerations. World Economy 21(3), 397-401.

Mayda, Anna Maria, 2010. International migration: A panel data analysis of the determinants of bilateral flows, Journal of Population Economics 23(4), 1249-1274.

McCullagh P. and J.A. Nelder, 1989. Generalized Linear Models. 2nd edition. CRC Monographs on Statistics \& Applied Probability. London and New York: Chapman \& Hall.

Millimet, Daniel L. and Thomas Osang, 2007. Do state borders matter for U.S. intranational trade? The role of history and internal migration. Canadian Journal of Economics 40(1), 93-126. 
Mundlak, Yair, 1978. On the pooling of time series and cross section data. Econometrica 46(1), 69-85.

Nilsson, Lars, 2000. Trade integration and the EU economic membership criteria. European Journal of Political Economy 16(4), 807-827.

Okawa, Yohei and Eric van Wincoop, 2013. Gravity in international finance. Journal of International Economics 87(2), 205-215.

Olivero Maria Pia and Yoto V. Yotov, 2012. Dynamic gravity: endogenous country size and asset accumulation, Canadian Economic Journal 45(1), 64-91.

Orefice, Gianluca, 2013. International Migration and Trade Agreements: the new role of PTAs. FIW Working Paper no 111. Centre d'Études Prospectives et d'Inormations Internationales, Paris.

Porojan, A., 2001. Trade flows and spatial effects: The gravity model revisited. Open Economies Review 12(3),265-280.

Pöyhönen, Pentti, 1963. A tentative model for the volume of trade between countries. Weltwirtschaftliches Archiv 90(1), 93-99.

Raymond, W., P. Mohnen, F. Palm, and S. Schim van der Loeff, 2010. Persistence of innovation in Dutch manufacturing: Is it spurious? Review of Economics and Statistics 92(3), 495-504.

Santos Silva, João M.C. and Silvana Tenreyro, 2006. The log of gravity. Review of Economics and Statistics 88(4), 641-658.

Santos Silva, João M.C. and Silvana Tenreyro, 2009. Trading partners and trading volumes: Implementing the Helpman-Melitz-Rubinstein model empirically. CEP Discussion Papers dp0935, London: Centre for Economic Performance, LSE. 
Santos Silva, João M.C. and Silvana Tenreyro, 2011. Further simulation evidence on the performance of the Poisson pseudo-maximum likelihood estimator. Economics Letters 112(2), 220-222.

Semykina A. and J.M. Wooldridge, 2010. Estimating panel data models in the presence of endogeneity and selection. Journal of Econometrics 157(2), 375-380.

Serlenga, Laura and Yongcheol Shin, 2007. Gravity models of intra-EU trade: application of the CCEP-HT estimation in heterogeneous panels with unobserved common time-specific factors. Journal of Applied Econometrics 22(2), 361-381.

Stock, James H. and M.W. Watson, 2008. Heteroskedasticity-robust standard errors for fixed effects panel data regression. Econometrica 76(1), 155-174.

Wamser, Georg, 2011. Foreign (in)direct investment and corporate taxation. Canadian Journal of Economics 44(4), 1497-1524.

Wansbeek, Tom and Arye Kapteyn, 1989. Estimation of the error-components model with incomplete panels. Journal of Econometrics 41(3), 341-61.

White, Halbert, 1982. Maximum likelihood estimation of misspecified models. Econometrica 50(1), 1-25.

Wooldridge, Jeffrey M., 1995. Selection corrections for panel data models under conditional mean independence assumptions. Journal of Econometrics 68(1), 115-132.

Wooldridge, Jeffrey M., 2003. Cluster-sample methods in applied econometrics. American Economic Review 93(2), 133-138.

Wooldridge, Jeffrey M., 2005. Simple solutions to the initial conditions problem in dynamic, nonlinear panel data models with unobserved heterogeneity. Journal of Applied Econometrics 20(1), 39-54. 
Wooldridge, Jeffery M. 2010. Econometric analysis of cross section and panel data. 2nd ed. Cambridge MA: MIT-Press.

Wyhowski, Donald J., 1994. Estimation of a panel data model in the presence of correlation between regressors and a two-way error component. Econometric Theory 10(1), 130-139. 